\title{
B1 Magnet Harmonics
}

\author{
P. Barnes
}

May 30, 2000

U.S. Department of Energy

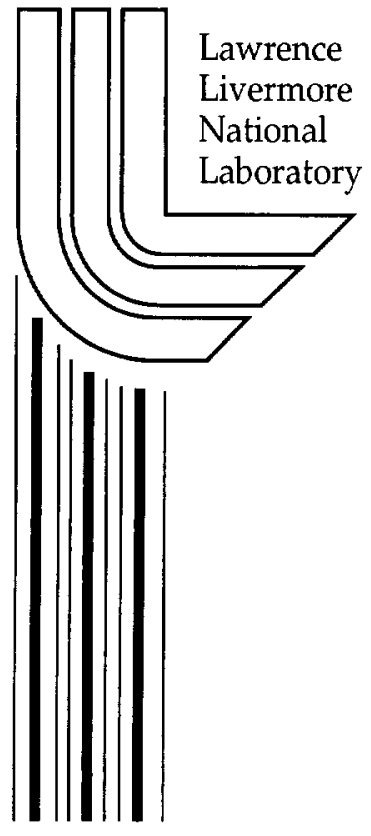




\section{DISCLAIMER}

This document was prepared as an account of work sponsored by an agency of the United States Government. Neither the United States Government nor the University of California nor any of their employees, makes any warranty, express or implied, or assumes any legal liability or responsibility for the accuracy, completeness, or usefulness of any information, apparatus, product, or process disclosed, or represents that its use would not infringe privately owned rights. Reference herein to any specific commercial product, process, or service by trade name, trademark, manufacturer, or otherwise, does not necessarily constitute or imply its endorsement, recommendation, or favoring by the United States Government or the University of California. The views and opinions of authors expressed herein do not necessarily state or reflect those of the United States Government or the University of California, and shall not be used for advertising or product endorsement purposes.

This work was performed under the auspices of the U. S. Department of Energy by the University of California, Lawrence Livermore National Laboratory under Contract No. W-7405-Eng-48.

This report has been reproduced directly from the best available copy.

Available electronically at http://www.doc.gov/bridge

Available for a processing fee to U.S. Department of Energy

And its contractors in paper from

U.S. Department of Energy

Office of Scientific and Technical Information

P.O. Box 62

Oak Ridge, TN 37831-0062

Telephone: (865) 576-8401

Facsimile: (865) 576-5728

E-mail: reports@adonis.osti.gov

Available for the sale to the public from

U.S. Department of Commerce

National Technical Information Service

5285 Port Royal Road

Springfield, VA 22161

Telephone: (800) 553-6847

Facsimile: (703) 605-6900

E-mail: orders@ntis.fedworld.gov

Online ordering: http://www.ntis.gov/ordering.htm

OR

Lawrence Livermore National Laboratory

Technical Information Department's Digital Library

http://www.llnl.gov/tid/Library.html 
UCRL-ID-xxxxxx

STRON-1999-023

Peter Barnes, LLNL

May 30, 2000

\title{
B1 Magnet Harmonics
}

\begin{abstract}
During the B0 Overpass construction for the CDF detector at Fermilab, 33 B1 magnets were measured using a bucked tangential coil. Measurements were made on the midplane, at the centerline and at \pm 1 " horizontal displacement. Since the coil was only 62 " long, measurements were made at four longitudinal positions. Because of the design of the Main Ring, it was sufficient to combine data from all positions and report the harmonic spectrum for the magnet as a whole. For modeling the Scrounge-atron, it is more useful to treat each measurement position separately. I report here an analysis of the harmonic spectra at each probe position, based on the original data.
\end{abstract}




\section{Contents}

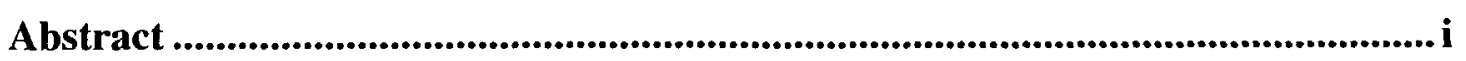

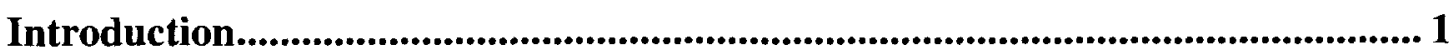

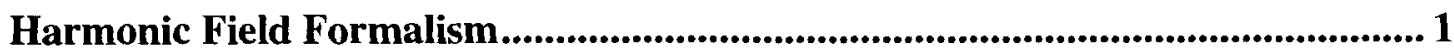

FNAL Measurements .................................................................................... 3

Measurement Probe .............................................................................. 3

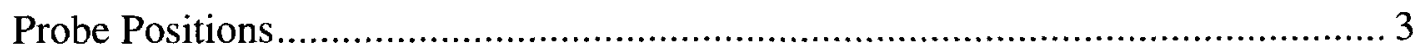

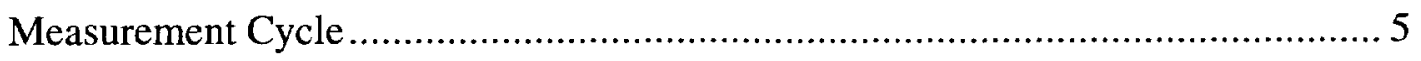

Data Acquisition and Preprocessing ................................................... 5

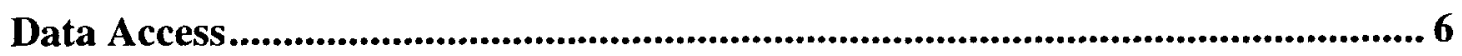

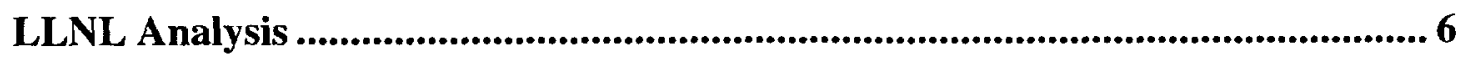

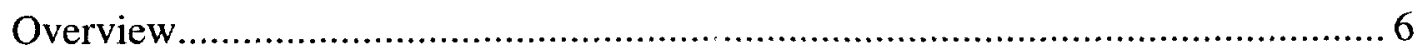

Selection of Central Core Data Set ........................................................... 7

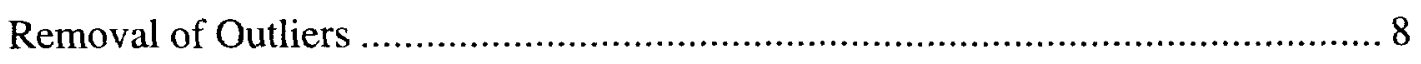

Scaling to Common Reference Field.......................................................... 9

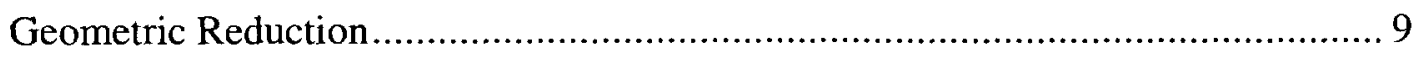

Analysis Parameters ......................................................................... 10

Guide to Results and Jump Table.................................................................. 11

Systematic Harmonics Tables ........................................................... 14

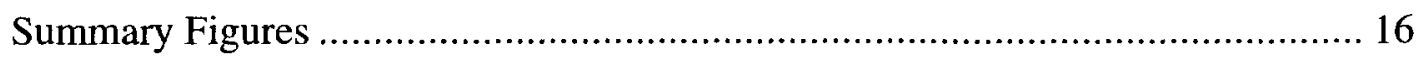

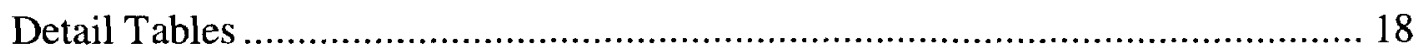

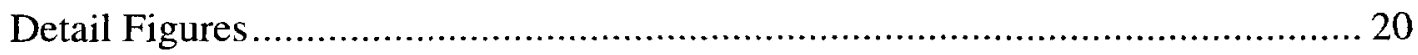

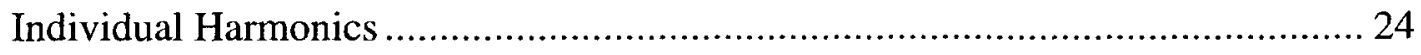

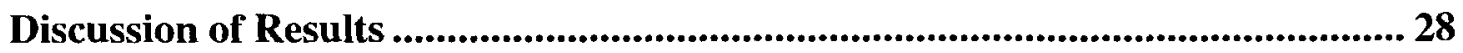


Fermilab B1 Magnet Harmonics

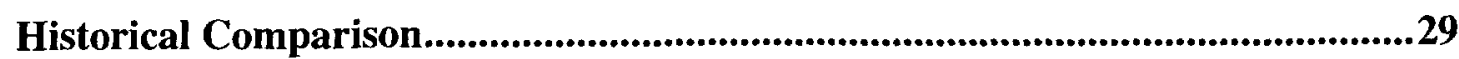

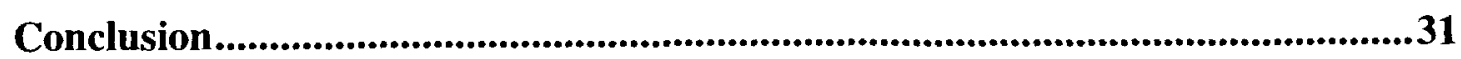

Appendix A: Workbook Sheet Summary ........................................................32

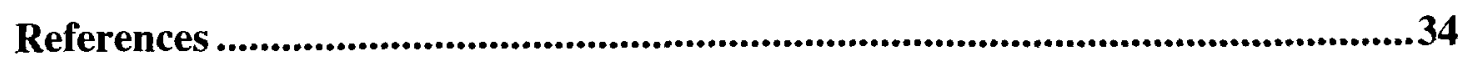




\section{Introduction}

During the B0 Overpass construction for the CDF detector at Fermilab, 33 B1 magnets from the Main Ring were measured using a bucked tangential coil. Measurements were made on the midplane, at the centerline and at \pm 1 " horizontal displacement. Since the coil was only 62" long, measurements were made at four longitudinal positions. Because of the design of the Main Ring, it was sufficient to combine data from all positions and report the harmonic spectrum for the magnet as a whole. For modeling the Scroungeatron, including the effects of its large sagitta, it is more useful to treat each measurement position separately. I report here an analysis of the harmonic spectra at each probe position, based on the original data.

I start with a brief introduction to the formalism of harmonic fields, in order to define the quantities of interest. After reviewing the FNAL measurement procedure and how I extracted the data, I discuss my analysis and results. The results are presented in both tabular and graphic form, plotted either $v s$. multipole number or dipole reference field (equivalent to the current). (The excitation curve is the subject of another note.) The jump table may be useful in finding specific presentations of the results.

I want to acknowledge and thank Bruce Brown, Dave Harding, and Peter Mazur at Fermilab for explaining the measurements, arranging my access to the database, and answering innumerable questions. I also want to thank Sandro Ruggiero, Sho Ohnuma, and Ed Hartouni for many useful discussions.

\section{Harmonic Field Formalism}

As is usually done (see Ref. [1] and references therein, and [2-4]), I consider transverse magnetic fields, i.e., fields in two dimensions, the $x-y$ plane. To see when such fields arise, consider the magnetostatic Maxwell equations[5, p. 176]:

$$
\begin{aligned}
\nabla \times \mathbf{B} & =\mu_{0} \mathbf{j} \\
\nabla \cdot \mathbf{B} & =0
\end{aligned}
$$

where $\mathbf{j}$ is the current density. Because of the second line, the magnetic field must be the curl of a vector potential, $\mathbf{A}$,

$$
\mathbf{B}=\nabla \times \mathbf{A}
$$

Choosing the Coulomb gauge by requiring $\nabla \cdot \mathbf{A}=0$, the potential can be computed from the current density by 
Fermilab B 1 Magnet Harmonics

$$
\mathbf{A}(\mathbf{r})=\frac{\mu_{0}}{4 \pi} \int \frac{\mathbf{j}}{\left|\mathbf{r}-\mathbf{r}^{\prime}\right|} d^{3} r^{\prime}
$$

If the current density is parallel to the $z$ axis, then the potential has only a $z$ component, and the magnetic field will be strictly transverse, that is, with non-zero $x$ and $y$ components, and $z$ component identically zero. Therefore I consider only the $x$ and $y$ components of the field, $B_{x}, B_{y}$, and ignore $B_{z}$ from here on.

I further specialize to magnetic fields in the gaps of dipole magnets, that is, in the absence of currents. Expanding Equation (1) in component form,

$$
\begin{gathered}
\frac{d B_{y}}{d z}=0 \quad \frac{d B_{x}}{d z}=0 \\
\frac{d B_{y}}{d x}=\frac{d B_{x}}{d y} \\
\frac{d B_{x}}{d x}=-\frac{d B_{y}}{d y}
\end{gathered}
$$

Equations (5) have a familiar form, that of the Cauchy-Riemann equations for analytic functions. This suggests that I work in the complex plain, with coordinate points represented by the complex coordinate

$$
w=x+i y=r e^{i \theta}
$$

where $r$ is the distance from the origin, and $\theta$ is the angle from the $x$ axis; and the magnetic field represented by the analytic complex function[6]

$$
B(w)=B_{y}(w)+i B_{x}(w)
$$

Alternatively, I can express the field as a power series, or multipole expansion, in $w$ :

$$
B(w)=\sum_{j=1}^{\infty} C_{j} w^{j-1}=\sum_{j=1}^{\infty}\left(\left|C_{j}\right| e^{i \chi_{j}}\right) r^{j-1} e^{i(j-1) \theta}
$$

Since the advent of strong focussing accelerators, most accelerator magnets have been separated function magnets, designed to produce all their field strength at a single multipole. That is, a single term, $j=n$, dominates the series. It is convenient therefore, to rotate the coordinate system to null the associated phase, $\chi_{n}=0$. At a point on the $x$ axis $(\theta=0)$ a distance $a$ from the origin, the dominant term gives a field strength

$$
B(w=a) \cong B_{n}(a)=\left|C_{n}\right| a^{n-1}
$$

It is conventional to rescale the coordinates by the length, $a$, and normalize the coefficients in the expansion to the dominant multipole, $B_{n}(a)$, to obtain

$$
B(w)=B_{n}(a) \sum_{j=1}^{\infty} c_{n}\left(\frac{r}{a}\right)^{j-1} e^{i(j-1) \theta},
$$


where the normalized (complex) harmonic coefficients, $c_{n}$, are defined by equating terms in Equations (8) and (10):

$$
c_{j}=\frac{\left|C_{j}\right|}{\left|C_{n}\right|} a^{j-n} e^{i\left(\chi_{j}-\chi_{n}\right)}=\frac{B_{j}(a)}{B_{n}(a)} .
$$

The normalized coefficients are the ratio of the multipole field $j$ to the dominant field, $B_{n}$, at the reference radius, $a$. The real and imaginary parts, $b_{j}$ and $a_{j}$

$$
c_{j}=b_{j}+i a_{j},
$$

are called the normal and skew components, respectively.

The output of the measurement procedure is the set of normalized coefficients, $c_{j}$, or the normal and skew components, as in Equation (12), which can be used to compute the field using Equation (10).

At the time of the measurements reported here, the reference radius was taken to be 1", and the harmonic coefficients were reported in FNAL units of $10^{-4}$, i.e., a coefficient of 1 unit represents a multipole field strength at 1 " radius of $10^{-4}$ of the dominant multipole at that radius. For example, a one unit quadrupole error measured in a dipole operated at 1 $\mathrm{kG}$ corresponds to a gradient error of $0.1 \mathrm{G} / \mathrm{inch}$ or $39.37 \mathrm{G} / \mathrm{m}$.

\section{FNAL Measurements}

Fermilab built the B0 overpass in the 1980's to bring the Main Ring over the CDF detector, which is wrapped around the Tevatron. This construction resulted in the removal of $\sim 33 \mathrm{Bl}$ dipoles. FNAL took the opportunity to apply modern harmonic measurement techniques to these magnets in order to improve their understanding of aperture limitations and resonances in the operation of the Main Ring as an injector to the Tevatron. These measurements were made during the approximate period June 1986 August 1989.

\section{Measurement Probe}

The measurements were made using a 62 " long rotating tangential coil, with belly band bucking coils. For a more complete description, see [7]. To my knowledge, a description of this coil has not been published.

\section{Probe Positions}

Since the probe was much shorter than the magnet, it was successively placed at four longitudinal positions, starting with $\sim 10^{\prime \prime}$ extending beyond one face, two positions well 
Fermilab B1 Magnet Harmonics

within the magnet, and a final position the mirror of the first, as sketched in Figure 1. With these four positions every $z$ coordinate is included in exactly one probe position. Because of the symmetrical placement of the probe positions in the longitudinal direction, there are only two unique longitudinal positions, "Body" and "End", as indicated in the figure.

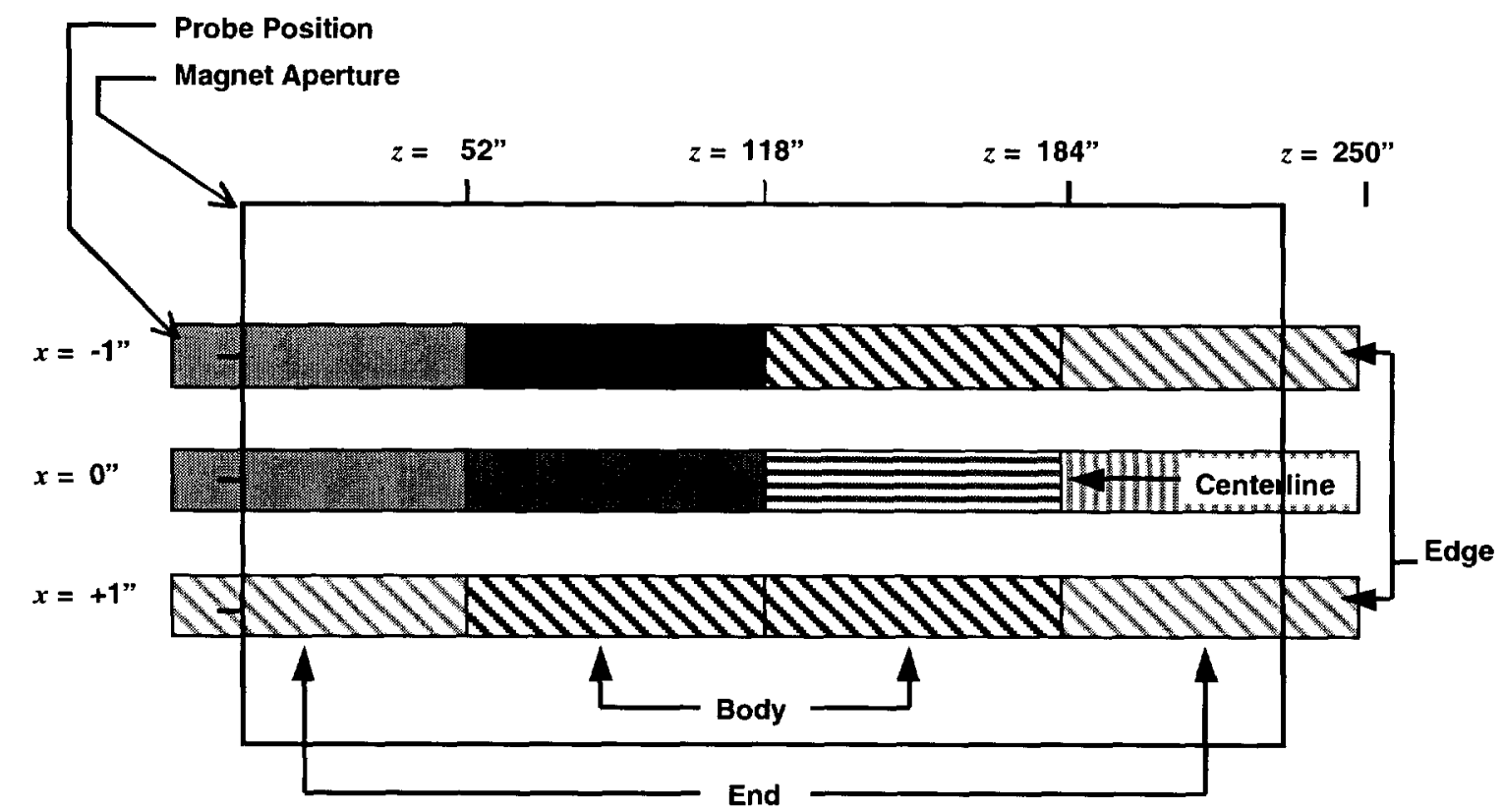

Figure 1. Schematic plan view of B1 magnet bore and probe positions. Positions are labeled longitudinally by the $z$ coordinate of the probe end, and transversely by the probe centerline. The positions of reported harmonics are shaded solid; geometrically similar positions (see main text) are striped with the corresponding color. Figure not to scale.

In the transverse direction, the probe was on the vertical midplane, and at one of three transverse positions, on the centerline $(x=0 ")$, and at $x= \pm 1^{\prime \prime}$. These are also shown schematically in Figure 1. A scale cross section is shown in Figure 2. Because of the symmetrical placement of the probe positions about the center line, there are only two unique transverse positions, "Centerline" and "Edge", as indicated in Figure 1. 


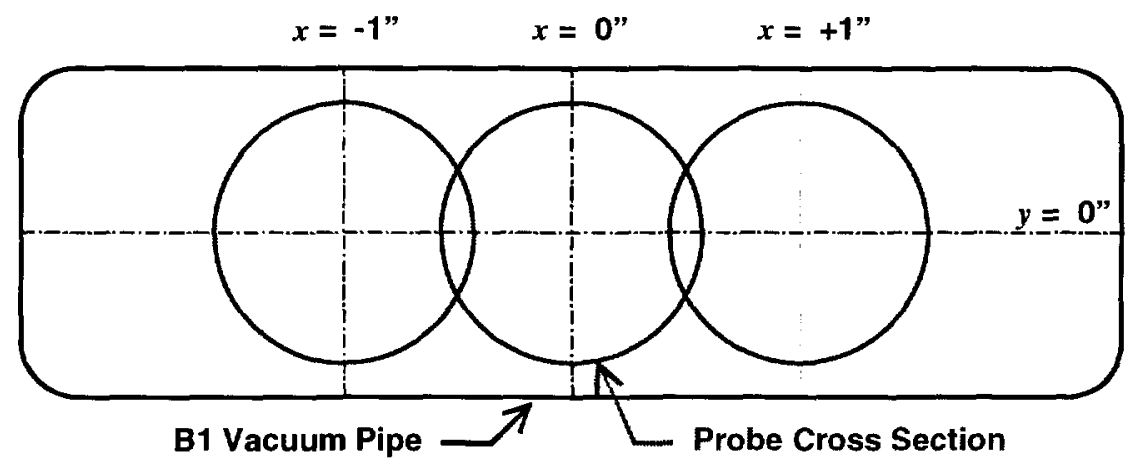

Figure 2. Schematic cross section view of $\mathrm{B} 1$ vacuum pipe and probe positions on the midplane at the center $\left(x=0^{\prime \prime}\right)$ and at $x= \pm 1$ ". Figure is approximately to scale.

Because of the symmetries noted above, there are only four distinct probe positions, Centerline Body, Centerline End, Edge Body, and Edge End. If the magnets are dominated by "allowed" field errors, then this geometric reduction should be reflected in the data.

\section{Measurement Cycle}

The measurements were made following the FNAL Magnet Test Facility (MTF) procedure given in [8].

The basic procedure was to ramp the magnet to $1700 \mathrm{~A}$ and back to zero four times, then, on the fifth ramp, halt at the desired measurement current $(0 \mathrm{~A}, 97 \mathrm{~A}, 210 \mathrm{~A}, 1700 \mathrm{~A})$ and make a reference (dipole) run and a harmonics run.

\section{Data Acquisition and Preprocessing}

The raw data from the integrator was preprocessed to produce normalized coefficients, normal and skew, out to $n=10$ (a total of 20 coefficients), in Fermilab units. These were assembled with run header information into a record in a VAX Datatrieve database.

The Fermilab convention at this time (late 1980's) was a multipole $n$ arises from a magnet with $2 n$ pole tips. That is, an $n=3$ multipole is a sextupole. (This differs from the original Fermilab convention of the 1970's, and agrees with the present CERN convention.)

Fermilab harmonic field strengths were reported at 1 " from the probe axis. Since we are dealing with dipoles here, all coefficients were normalized to the dipole field measured at the same time as the harmonic field. Finally, Fermilab coefficients were reported in units - a part in $10^{4}$. Therefore, a one unit quadrupole error measured in a dipole operated at 1 $\mathrm{kG}$ corresponds to a gradient error of $0.1 \mathrm{G} / \mathrm{inch}$ or $39.37 \mathrm{G} / \mathrm{m}$. 


\section{Data Access}

The database currently resides on two machines at FNAL, the Magnet Test Facility production machine, and a controls group cluster, which was my primary access (specifically cns55. fnal.gov). Data were acquired at each probe position at least twice, in most cases. The "best" data at each position were then summed longitudinally and reported in the HSUM domain of the database. Starting with these sums, I backtracked through the HSUMPTR domain to the original probe measurements in domains MRDHARM and MRDGOOD, using the procedure in [9].

The raw output files are available upon request.

\section{LLNL Analysis}

\section{Overview}

My analysis proceeded through four basic steps: selection of a central "core" data set, identification and removal of outlier harmonic values and magnet mountings, scaling all harmonics to a common reference field, and geometric reduction. I will describe each of these steps below. Identifying outliers was the most involved step. I compared individual coefficients to the statistics of the "core" data, rejecting coefficients if the deviation was extreme. By comparing to the "core" statistics, outliers did not contribute to the criteria used to eliminate them, eliminating a potential source of bias.

The raw data for harmonic amplitude has four dimensions: nominal current, probe position, magnet serial number, and harmonic number. For most of the analysis (up to geometric reduction) I treated each current and probe position separately. I further split the measurements with a given probe position according to the position of the third coil, up or down, since Bruce Brown and Dave Harding had warned me that this affects some multipoles at the ends.[10] Therefore, the analysis considers one probe position at one nominal current setting for a set of magnets with the same third coil position. Each set contained either 18 magnets (third coil down, including the reference magnet, ADM005 measured twice) or 16 magnets (third coil up). The specific magnets measured are listed in Table 1. 
Table 1. Serial numbers of magnets used in this analysis.

\begin{tabular}{|l|l|l|l|l|l|}
\hline \multicolumn{3}{|c|}{ Third Coil Down } & \multicolumn{3}{c|}{ Third Coil Up } \\
\hline ADM005 & ADM292 & ADM336 & ADM509 & ADM854 & ADM864 \\
\hline ADM031 & ADM322 & ADM344 & ADM576 & ADM855 & ADM866 \\
\hline ADM032 & ADM328 & ADM345 & ADM731 & ADM860 & ADM867 \\
\hline ADM119 & ADM330 & ADM346 & ADM796 & ADM861 & ADM868 \\
\hline ADM243 & ADM331 & ADM347 & ADM798 & ADM862 & \\
\hline ADM285 & ADM334 & & ADM809 & ADM863 & \\
\hline
\end{tabular}

I performed the analysis in Excel 98 workbooks, one for each nominal current, which are also available upon request.

These workbooks contain 17 sheets and occupy $8.4 \mathrm{MB}$ on disk. As the analysis developed, I added sheets for derived data to the left of the source sheets, so the highest level results appear "first" in the workbook. To simplify the discussion below, however, I will refer to the rightmost tab, containing the raw data, as the first sheet, the adjacent sheet (to the left) as the next sheet, and so on. Sheet names will be shown like this. For a summary of the calculations performed on each sheet, see Appendix A: Workbook Sheet Summary.

\section{Selection of Central Core Data Set}

I put the raw DATATRIEVE output into the first Excel workbook tab, Raw.

To select and filter the data, I analyzed each current, and each probe position separately. In addition, since $I$ had been told to expect differences due to the third coil, I analyzed third coil up separately from third coil down.

I grouped the data for each probe position and third coil position into an outline, with summary statistics, on the next sheet, Grouped.

The raw data consists of the $i^{\text {th }}$ harmonic coefficient (multipole coefficient) for the $j^{\text {th }}$ magnet (serial number) at this nominal current and probe position (and position of third coil). Call this raw data $a_{i, j}$. In Grouped I computed the mean, $\left\langle a_{i, j}\right\rangle_{j}$, and r.m.s. deviation, $\sigma_{a_{i, j} \mid j}$, for each harmonic (computed over the individual magnets, $j$ ).

Then, in Raw $t$, I computed the t-scores:

$$
t_{i, j}=\left(a_{i, j}-\left\langle a_{i, j}\right\rangle_{j}\right) / \sigma_{a_{i, j} l j} .
$$




\section{Fermilab B1 Magnet Harmonics}

This is the deviation of a given harmonic from the mean across magnets for this harmonic, normalized to the scatter. Finally, I computed the mean of these t-scores for each magnet, across multipoles, to derive a figure of merit for the magnet, $\left\langle t_{i, j}\right\rangle_{i}$.

I masked off data for any magnet with $\left\langle t_{i, j}\right\rangle_{i}>1.0$, retaining the "core" of the data set in cut t. Acceptances for this and subsequent cuts are shown in Table 2. This was intended to be a strong cut, so as to remove all possible outliers, accepting the risk of removing some good data. (By inspection of Table 2, it is clear that I could (should?) have made this cut even more restrictive, down to an acceptance of $70 \%$, say.)

In Cut Raw I returned to the harmonic coefficients, but only for magnets that passed the cut $t$ mask; call these $a_{i, j}^{\prime}$. At this point I recomputed the mean, $\left\langle a_{i, j}^{\prime}\right\rangle_{j}$, and r.m.s. deviation, $\sigma_{a_{i, j}^{\prime} \mid j}$, for each coefficient, as was done in Grouped, but now only over the core of the data set. These restricted statistics form the basis for rejecting outliers in an unbiased way.

\section{Removal of Outliers}

Using these restricted statistics I computed a modified t-score in $t^{\prime}$ Scores:

$$
t_{i, j}^{\prime}=\left(a_{i, j}-\left\langle a_{i, j}^{\prime}\right\rangle_{j}\right) / \sigma_{a_{i, j}^{\prime} l j} .
$$

$t^{\prime}$ Distr shows the distribution and integral of $t_{i, j}^{\prime}$, and an approximate Gaussian fit. These curves show most of the measurements normally distributed and a long tail of outliers. Using the curves as a guide, I set a cut on $t_{i, j}^{\prime}$ at 3.00 to remove the long tail of the distribution. $t$ ' cut shows the coefficients surviving the cut.

Since the coefficients are the Fourier transform of the voltage $v s$. position angle of the probe, a faulty measurement will likely result in many anomalous coefficients. Turning this around, if a magnet has too few coefficients surviving the cut on $t_{i, j}^{\prime}$ I should discard all the coefficients, since they are likely derived from a bad measurement. To implement this, $t^{\prime}$ Distr computes the number of coefficients surviving the $t_{i, j}^{\prime}$ cut, $N_{t_{i, j}^{\prime} j}$, for each magnet.

\# Distr plots the distribution and integral of $N_{t_{i, j}^{\prime} j}$, along with an approximate Gaussian fit. As before, the data show most of the measurements normally distributed and a long tail of measurements with many coefficients cut. Using the curves as a guide, I set a cut on $N_{t_{i, j}, j}$ at 17 to remove the long tail.

$t^{\prime}$-scores for magnets that pass this final cut are shown in \# cut, then are converted back to coefficients in Filtered. These represent the valid data for analysis. 


\section{Scaling to Common Reference Field}

I scale all coefficients to a common reference field, using the relation

$$
\tilde{a}_{i, j}=a_{i, j} \frac{\left(B_{0} \ell\right)_{j}}{B_{0} \ell^{*}},
$$

where $\left(B_{0} \ell\right)$ is the DIPOLE REFERENCE FIELD from the database, and $\ell^{*}$ is the effective probe length, 52" for the end positions and 62" for the body positions. The common scaling field, from the top of the scaled sheet, is listed in Table 2.

\section{Geometric Reduction}

Rol lup summarizes all coefficients and performs the geometric reduction.

By inspection of the coefficients obtained in Scaled, I verified my expectation from the magnet and probe position symmetries, that, up to a few overall signs, there are only four distinct harmonic spectra. Further, only half the coefficients change between any adjacent pairs of probe positions. The resulting spectra can be labeled: normal centerline, normal edge, skew body, and skew end. These will be discussed further in the Discussion section. To perform this geometric reduction I combined the redundant positions with due respect for the signs.

For the edge measurements for each multipole I computed the r.m.s. width of the distribution assuming that the $x=-1$ " measurements have either the same sign or opposite sign as the $x=+1$ " measurements. I chose the same sign unless the opposite sign results in a significant reduction in the width (By significant I mean larger than about 20\% reduction. Admittedly this criterion is not rigorously quantitative.) In either case I combined the results and report the $x=+1$ " sign.

Up to this point, I treated the third coil up measurements separately from the third coil down, computing $\alpha_{i}^{\mathrm{UP}}$ separately from $\alpha_{i}^{\mathrm{DN}}$ for the $i^{\text {th }}$ multipole. Now I examined the difference between these two coefficients normalized to the r.m.s. width of the combined distribution:

$$
\frac{\alpha_{i}^{\mathrm{UP}}-\alpha_{i}^{\mathrm{DN}}}{\sigma_{\alpha^{\mathrm{UP}} \pm \alpha^{\mathrm{DN}}}}
$$

If this quantity exceeded 0.8 and the two means had opposite signs, I considered the difference significant. Then I combined $\alpha_{i}^{\mathrm{UP}}$ and $-\alpha_{i}^{\mathrm{DN}}$ and report the sign of $\alpha_{i}^{\mathrm{UP}}$.

(After some algebra, the r.m.s. width of the combined distribution can be written

$$
(N-1) \sigma^{2}=N_{\mathrm{UP}}\left(\mu_{\mathrm{UP}}^{2}+\sigma_{\mathrm{UP}}^{2}\right)-\sigma_{\mathrm{UP}}^{2}+N_{\mathrm{DN}}\left(\mu_{\mathrm{DN}}^{2}+\sigma_{\mathrm{DN}}^{2}\right)-\sigma_{\mathrm{DN}}^{2}-N \mu^{2}
$$


where $N_{\mathrm{UP}}, \mu_{\mathrm{UP}}$, and $\sigma_{\mathrm{UP}}$ are the number of magnets, mean, and r.m.s. width of the distribution for magnets with the third coil up, and similarly for down (DN), and $N, \mu$, and $\sigma$ are the total number of magnets, the overall mean (computed with some choice for the relevant sign), and the r.m.s. width of the combined distribution. If the sign choice made is incorrect, then $\mu$ will be very small and $\sigma$ will be large since the last term will not offset the previous terms.)

Finally, by inspection of Figures 7-14 I determined that only the normal harmonics change in moving the probe from center to edge, and only the skew harmonics change in moving the probe from body to end, so I combined all normal harmonic data on the centerline (NC), all normal harmonic data at the edges (NE), all skew harmonic data in the body (SB), and all skew harmonic data at the ends (SE).

As an example, consider the data taken at $97 \mathrm{~A}$, which is normalized to $395 \mathrm{G}$. I plot the normal harmonic coefficients in Figure 9 and the skew harmonic coefficients in Figure 10. Each of the four probe positions (centerline body, centerline end, edge body, edge end) is represented in each plot as a separate colored curve. The points on each curve are displaced horizontally from the gridline for clarity. The error bars show the r.m.s. width of the distribution.

For the normal coefficients on centerline, it is clear that the spectrum is the same in the body and at the ends of the magnets, so I combined these data to form the black curve labeled Centerline. This is the last step in the geometric reduction. I performed similar reductions for the normal coefficients at the edges, the skew coefficients in the body, and the skew coefficients at the ends.

\section{Analysis Parameters}

The various parameters, cuts, and acceptances discussed above are listed in Table 2. 
Table 2. Parameters, cuts, and resulting acceptances.

\# Msmts. for a given spectrum is the average number of individual measurement coefficients that passed the cuts and were used to calculate the mean and r.m.s. width for each resultant harmonic coefficient. The standard deviation on this number ranges from $0.3-2$, so is negligible.

\begin{tabular}{|c|c|c|c|c|}
\hline \multirow{2}{*}{ Parameter } & \multicolumn{4}{|c|}{ Nominal Current } \\
\cline { 2 - 5 } & $\mathbf{0 ~ A}$ & $\mathbf{9 7} \mathbf{A}$ & $\mathbf{2 1 0} \mathbf{A}$ & $\mathbf{1 7 0 0} \mathbf{A}$ \\
\hline Cut $t$ Acceptance & 0.765 & 0.819 & 0.846 & 0.777 \\
\hline$t_{i, j}^{\prime}$ Cut Value & 3.00 & 3.00 & 3.00 & 3.00 \\
\hline$t_{i, j}^{\prime}$ Acceptance & 0.936 & 0.912 & 0.896 & 0.920 \\
\hline$N_{t_{i, j}, j}$ Cut Value & 17 & 17 & 17 & 17 \\
\hline$N_{t_{i, j}^{\prime} j}$ Acceptance & 0.906 & 0.913 & 0.909 & 0.880 \\
\hline Net Coefficient Acceptance & 0.848 & 0.833 & 0.814 & 0.810 \\
\hline \# Msmts. For NC & 116 & 116 & 115 & 108 \\
\hline \# Msmts. For NE & 231 & 225 & 218 & 223 \\
\hline \# Msmts. For SB & 170 & 168 & 163 & 168 \\
\hline \# Msmts. For SE & 177 & 173 & 170 & 163 \\
\hline Net Magnet Acceptance & 0.855 & 0.838 & 0.819 & 0.816 \\
\hline Scaling Field (G) & 17 & 395 & 840 & 6750 \\
\hline
\end{tabular}

\section{Guide to Results and Jump Table}

I show the complete set of harmonics at all four currents in various graphs and tables below. I list all coefficients at each current in Tables 6.1-6.4, and the significant systematic (non-zero) harmonics in Tables 5.1-5.4. I plot the normal and skew coefficients at each current as well as each coefficient as a function of current. Each presentation is described below. The jump table, Table 4, may be useful in finding specific presentations of the results.

The tables give all four spectra (normal centerline, normal edge, skew body, skew end) at one reference field (nominal current). The dipole entries are grayed out, since they merely show the accuracy of the bucking during the measurement.

The coefficients are color coded to indicate whether they differ significantly from zero and whether a sign change (for edges or third coil position) was used in the reduction. These are illustrated in Table 3. Coefficients in red type exceed the r.m.s width in magnitude, those in black type exceed half the r.m.s. width, and those in gray type are less than half the r.m.s. width in magnitude. Cells shaded yellow indicate that the $x=-1$ " 
Fermilab B1 Magnet Harmonics

values have the opposite sign from the $x=+1$ " value shown. Cells shaded aqua indicate that magnets with the third coil down have the opposite sign from the third coil up value shown.

Table 3. Coefficient Significance and Sign Change Color Codes in Tables 5 and 6.

\begin{tabular}{|c|c|c|c|}
\hline Significance & $b_{\text {or } a_{i}<\frac{\sigma_{i}}{2}}$ & $\frac{\sigma_{i}}{2}<b_{i}$ or $a_{i}<\sigma_{i}$ & $\sigma_{i}<b_{i}$ or $a_{i}$ \\
\hline Sign Changes & $x= \pm 1^{\prime \prime}$ & & $\begin{array}{c}\text { Third Coil } \\
\text { Up or Down }\end{array}$ \\
\hline
\end{tabular}

Systematic Harmonics, Table 5, lists only the coefficients that exceed $\sigma_{i} / 2$ in magnitude (black or red type).

Summary Figures, Figures 3-6 show the final four harmonic spectra, normal centerline (NC), normal edge (NE), skew body (SB), and skew end (SE). Each plot shows four curves, one for each reference field (nominal measurement current).

Detail Tables, Table 6, give all four spectra (normal centerline, normal edge, skew body, skew end) at one reference field (nominal current). Each entry consists of the mean and r.m.s. width of the distribution, color coded as discussed above.

Detail Figures, Figures 7-14, show the normal or skew harmonics at each current. Each plot shows a curve for each unique probe position (centerline body, centerline end, edge body, edge end) and the result of summing each relevant pair (for normal harmonics, the centerline and edge positions, for skew harmonics the body and end positions), to form the final four harmonic spectra, normal centerline, normal edge, skew body, skew end. The points on each curve are displaced horizontally from the gridline for clarity. The error bars show the r.m.s. width of the distribution.

Finally, Individual Harmonics, Figures 15-23 show a single multipole, both normal and skew harmonic coefficients for a single value of $n$, as a function of reference field. 
Table 4. Jump Table.

\begin{tabular}{|c|c|c|c|c|}
\hline $\begin{array}{c}\text { Systematic Harmonics } \\
\text { Tables } 5\end{array}$ & $\begin{array}{l}\text { Table } 5.1 \\
17 \mathrm{G}\end{array}$ & $\begin{array}{c}\text { Table } 5.2 \\
395 \mathrm{G}\end{array}$ & $\begin{array}{c}\text { Table } 5.3 \\
840 \mathrm{G}\end{array}$ & $\begin{array}{c}\text { Table } 5.4 \\
6750 \mathrm{G}\end{array}$ \\
\hline $\begin{array}{l}\text { Summary Figures } \\
\text { Figures 3-6 }\end{array}$ & $\begin{array}{c}\text { Figure } 3 \\
\text { Normal } \\
\text { Centerline }\end{array}$ & $\begin{array}{l}\text { Figure } 4 \\
\text { Normal } \\
\text { Edge }\end{array}$ & $\begin{array}{l}\text { Figure } 5 \\
\text { Skew } \\
\text { Body }\end{array}$ & $\begin{array}{l}\text { Figure } 6 \\
\text { Skew } \\
\text { End }\end{array}$ \\
\hline $\begin{array}{l}\text { Detail Tables } \\
\text { Tables } 6\end{array}$ & $17 \mathrm{G}$ & $395 \mathrm{G}$ & $840 \mathrm{G}$ & $6750 \mathrm{G}$ \\
\hline $\begin{array}{l}\text { Detail Figures, } \\
\text { Normal Harmonic } \\
\text { Figures 7-13, odd }\end{array}$ & $\begin{array}{l}\text { Figure } 7 \\
17 \mathrm{G}\end{array}$ & $\begin{array}{l}\text { Figure } 9 \\
395 \mathrm{G}\end{array}$ & $\begin{array}{l}\text { Figure } 11 \\
840 \mathrm{G}\end{array}$ & $\begin{array}{c}\text { Figure } 13 \\
6750 \mathrm{G}\end{array}$ \\
\hline $\begin{array}{c}\text { Detail Figures, } \\
\text { Skew Harmonic } \\
\text { Figures 8-14,even }\end{array}$ & $\begin{array}{l}\text { Figure } 8 \\
17 \mathrm{G}\end{array}$ & $\begin{array}{l}\text { Figure } 10 \\
395 \mathrm{G}\end{array}$ & $\begin{array}{l}\text { Figure } 12 \\
840 \mathrm{G}\end{array}$ & $\begin{array}{c}\text { Figure } 14 \\
6750 \mathrm{G}\end{array}$ \\
\hline \multirow{3}{*}{$\begin{array}{l}\text { Individual Harmonic } \\
\text { Figures 15-23 }\end{array}$} & $\begin{array}{l}\text { Figure } 15 \\
n=2\end{array}$ & $\begin{array}{c}\text { Figure } 16 \\
n=3\end{array}$ & $\begin{array}{c}\text { Figure } 17 \\
n=4\end{array}$ & $\begin{array}{c}\text { Figure } 18 \\
n=5\end{array}$ \\
\hline & $\begin{array}{c}\text { Figure } 19 \\
n=6\end{array}$ & $\begin{array}{c}\text { Figure } 20 \\
n=7\end{array}$ & $\begin{array}{c}\text { Figure } 21 \\
n=8\end{array}$ & $\begin{array}{c}\text { Figure } 22 \\
n=9\end{array}$ \\
\hline & $\begin{array}{l}\text { Figure } 23 \\
n=10\end{array}$ & & & \\
\hline
\end{tabular}


Fermilab B1 Magnet Harmonics

\section{Systematic Harmonics Tables}

Table 5.1. Systematic Harmonics at $17 \mathrm{G}$.

\begin{tabular}{|c|c|c|c|c|c|c|}
\hline \multirow{2}{*}{ Harmonic } & \multicolumn{4}{|c|}{ Normal } & \multicolumn{3}{c|}{ Skew } \\
\cline { 2 - 7 } & $i$ & Centerline & Edge & $i$ & Body & End \\
\hline Quadrupole & $b_{2}$ & 31.4 & -310.1 & $a_{2}$ & 13.7 & 17.1 \\
\hline Sextupole & $b_{3}$ & -197.2 & -109.6 & $a_{3}$ & & \\
\hline Octupole & $b_{4}$ & -8.5 & 31.2 & $a_{4}$ & -10.8 & \\
\hline Decapole & $b_{5}$ & 43.8 & 9.9 & $a_{5}$ & & \\
\hline Dodecapole & $b_{6}$ & 11.3 & & $a_{6}$ & 12.3 & 14.3 \\
\hline$n=7$ Pole & $b_{7}$ & -26.1 & -13.1 & $a_{7}$ & & \\
\hline$n=8$ Pole & $b_{8}$ & & & $a_{8}$ & & \\
\hline$n=9$ Pole & $b_{9}$ & & & $a_{9}$ & & \\
\hline$n=10$ Pole & $b_{10}$ & & & $a_{10}$ & & \\
\hline
\end{tabular}

Table 5.2. Systematic Harmonics at 395 G.

\begin{tabular}{|c|c|c|c|c|c|c|}
\hline \multirow{2}{*}{ Harmonic } & \multicolumn{3}{|c|}{ Normal } & \multicolumn{3}{c|}{ Skew } \\
\cline { 2 - 7 } & $i$ & Centerline & Edge & $i$ & Body & End \\
\hline Quadrupole & $b_{2}$ & 1.3 & -10.1 & $a_{2}$ & 0.8 & -7.2 \\
\hline Sextupole & $b_{3}$ & -8.0 & -3.0 & $a_{3}$ & & \\
\hline Octupole & $b_{4}$ & -0.9 & 1.0 & $a_{4}$ & & -0.7 \\
\hline Decapole & $b_{5}$ & 4.2 & 0.6 & $a_{5}$ & & \\
\hline Dodecapole & $b_{6}$ & 1.7 & & $a_{6}$ & 1.0 & 1.1 \\
\hline$n=7$ Pole & $b_{7}$ & -4.0 & & $a_{7}$ & & \\
\hline$n=8$ Pole & $b_{8}$ & & & $a_{8}$ & & \\
\hline$n=9$ Pole & $b_{9}$ & 4.0 & & $a_{9}$ & & \\
\hline$n=10$ Pole & $b_{10}$ & & & $a_{10}$ & & \\
\hline
\end{tabular}


Table 5.3. Systematic Harmonics at $840 \mathrm{G}$.

\begin{tabular}{|c|c|c|c|c|c|c|}
\hline \multirow{2}{*}{ Harmonic } & \multicolumn{3}{|c|}{ Normal } & \multicolumn{3}{c|}{ Skew } \\
\cline { 2 - 7 } & $i$ & Centerline & Edge & $i$ & Body & End \\
\hline Quadrupole & $b_{2}$ & 0.7 & -3.9 & $a_{2}$ & & -7.1 \\
\hline Sextupole & $b_{3}$ & -3.9 & & $a_{3}$ & & \\
\hline Octupole & $b_{4}$ & -0.7 & & $a_{4}$ & & \\
\hline Decapole & $b_{5}$ & 3.2 & & $a_{5}$ & & \\
\hline Dodecapole & $b_{6}$ & 1.4 & & $a_{6}$ & & \\
\hline$n=7$ Pole & $b_{7}$ & -3.5 & -1.3 & $a_{7}$ & & \\
\hline$n=8$ Pole & $b_{8}$ & & & $a_{8}$ & & \\
\hline$n=9$ Pole & $b_{9}$ & 3.0 & & $a_{9}$ & & \\
\hline$n=10$ Pole & $b_{10}$ & & & $a_{10}$ & & \\
\hline
\end{tabular}

Table 5.4. Systematic Harmonics at $6750 \mathrm{G}$.

\begin{tabular}{|c|c|c|c|c|c|c|}
\hline \multirow{2}{*}{ Harmonic } & \multicolumn{3}{|c|}{ Normal } & \multicolumn{3}{c|}{ Skew } \\
\cline { 2 - 7 } & $i$ & Centerline & Edge & $i$ & Body & End \\
\hline Quadrupole & $b_{2}$ & 0.3 & & $a_{2}$ & & -7.1 \\
\hline Sextupole & $b_{3}$ & -1.5 & & $a_{3}$ & & \\
\hline Octupole & $b_{4}$ & -0.7 & & $a_{4}$ & & -0.5 \\
\hline Decapole & $b_{5}$ & 2.6 & & $a_{5}$ & & \\
\hline Dodecapole & $b_{6}$ & 1.3 & & $a_{6}$ & & \\
\hline$n=7$ Pole & $b_{7}$ & -3.3 & -0.7 & $a_{7}$ & & \\
\hline$n=8$ Pole & $b_{8}$ & -1.4 & & $a_{8}$ & & \\
\hline$n=9$ Pole & $b_{9}$ & 3.4 & & $a_{9}$ & & \\
\hline$n=10$ Pole & $b_{10}$ & & & $a_{10}$ & & \\
\hline
\end{tabular}


Fermilab B1 Magnet Harmonics

\section{Summary Figures}

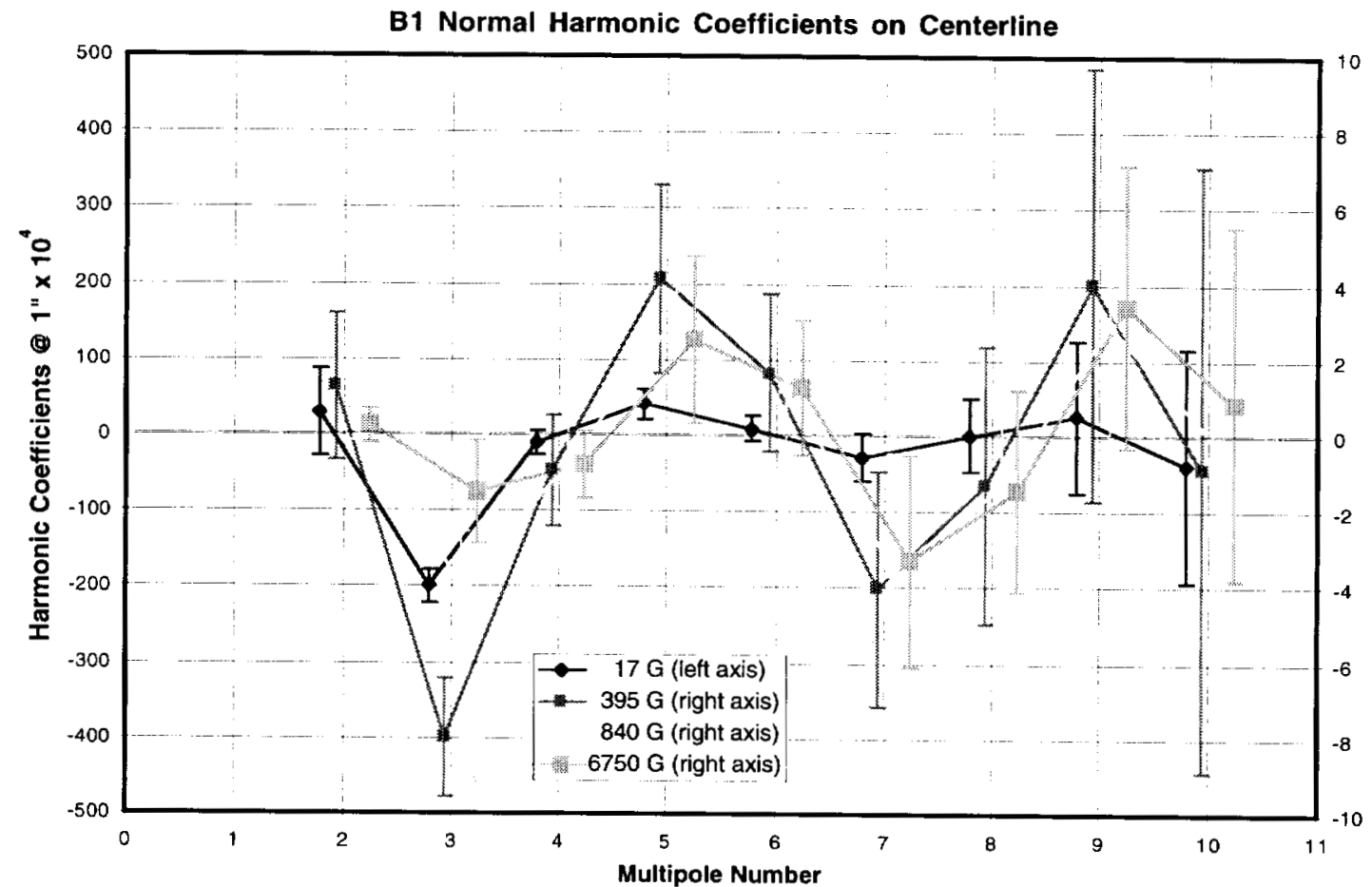

Figure 3. Normal Harmonics on the Centerline.

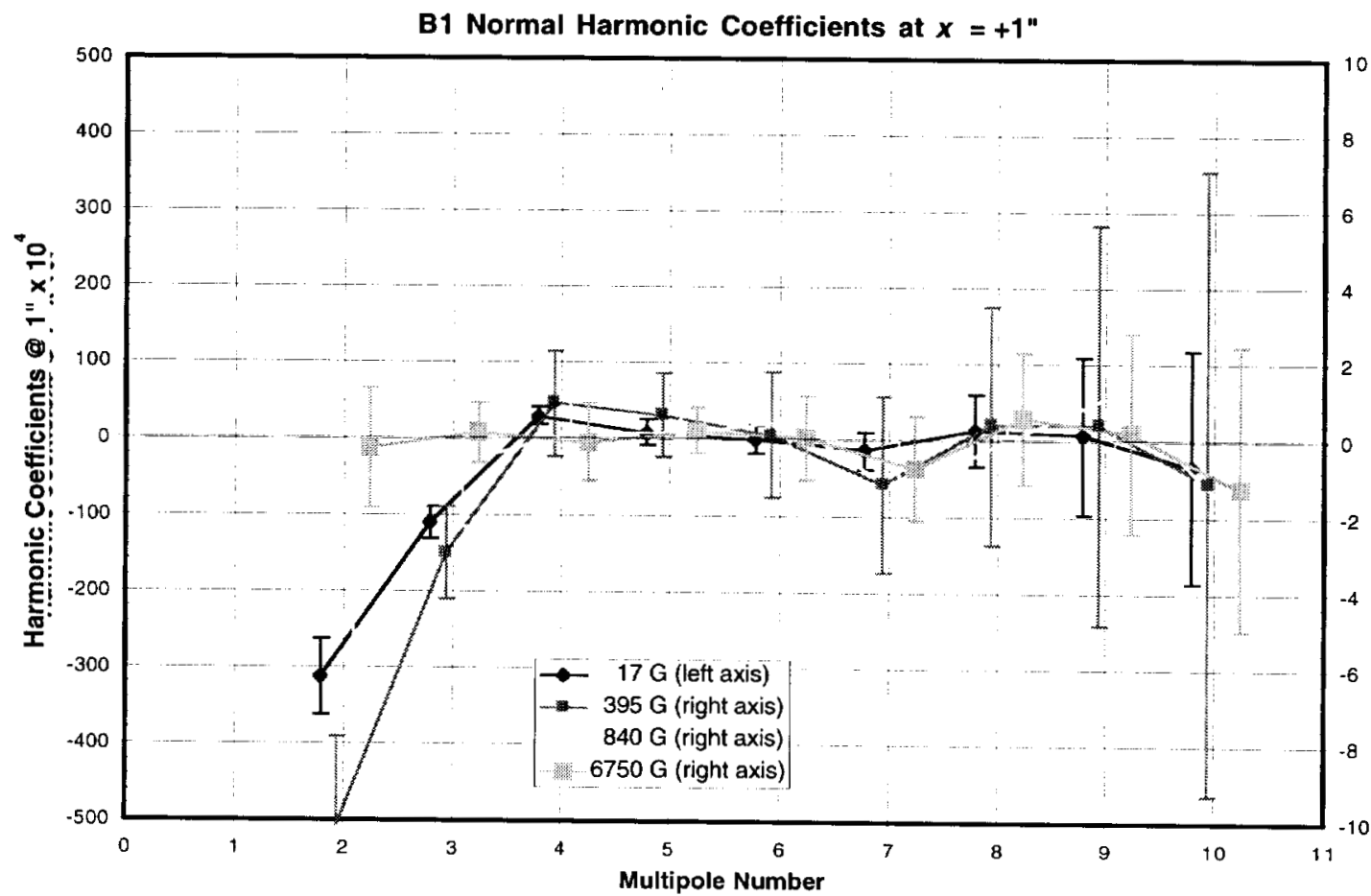

Figure 4. Normal Harmonics at the $x=+1$ " Edge. 


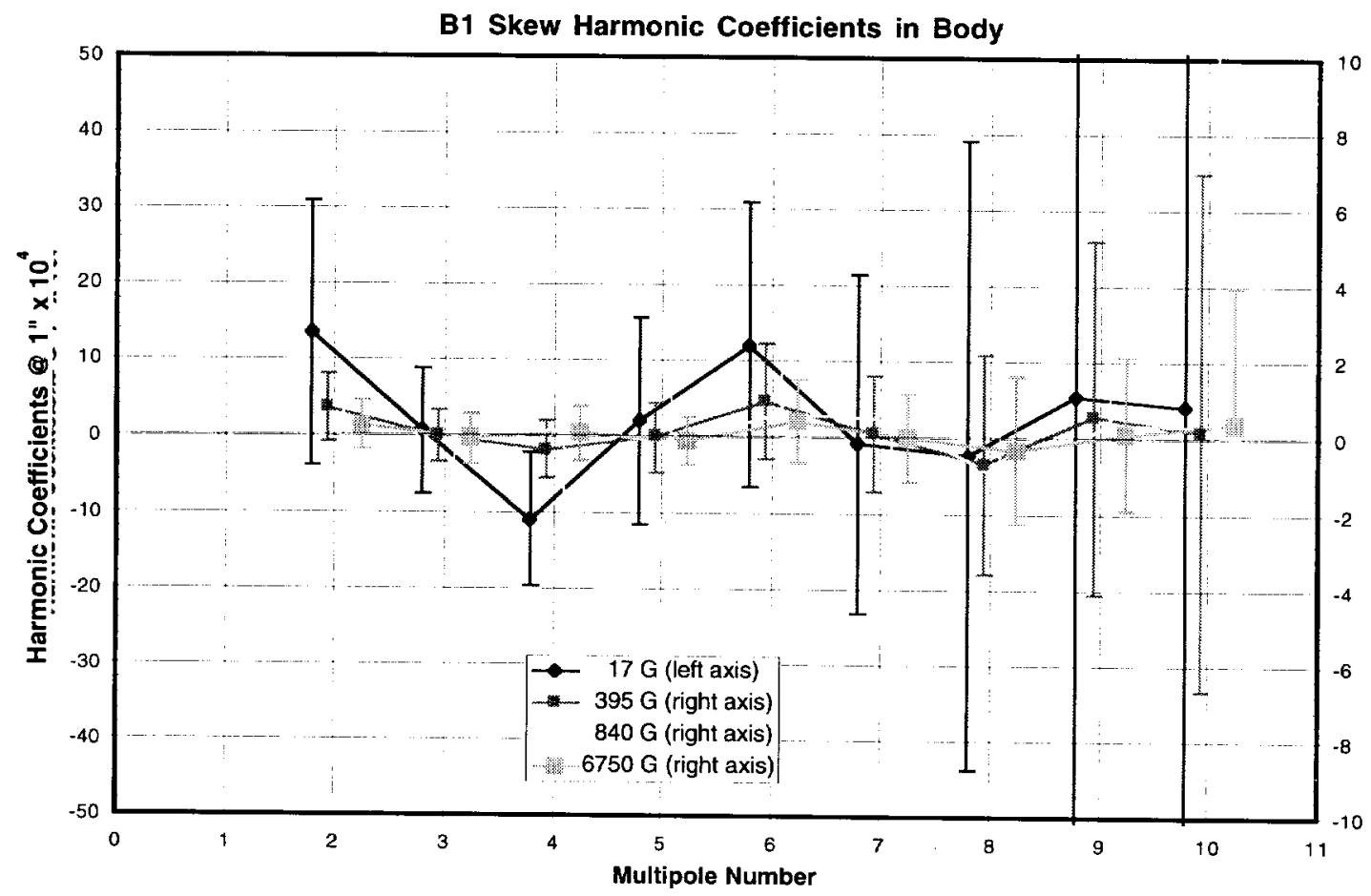

Figure 5. Skew Harmonics in the Body.

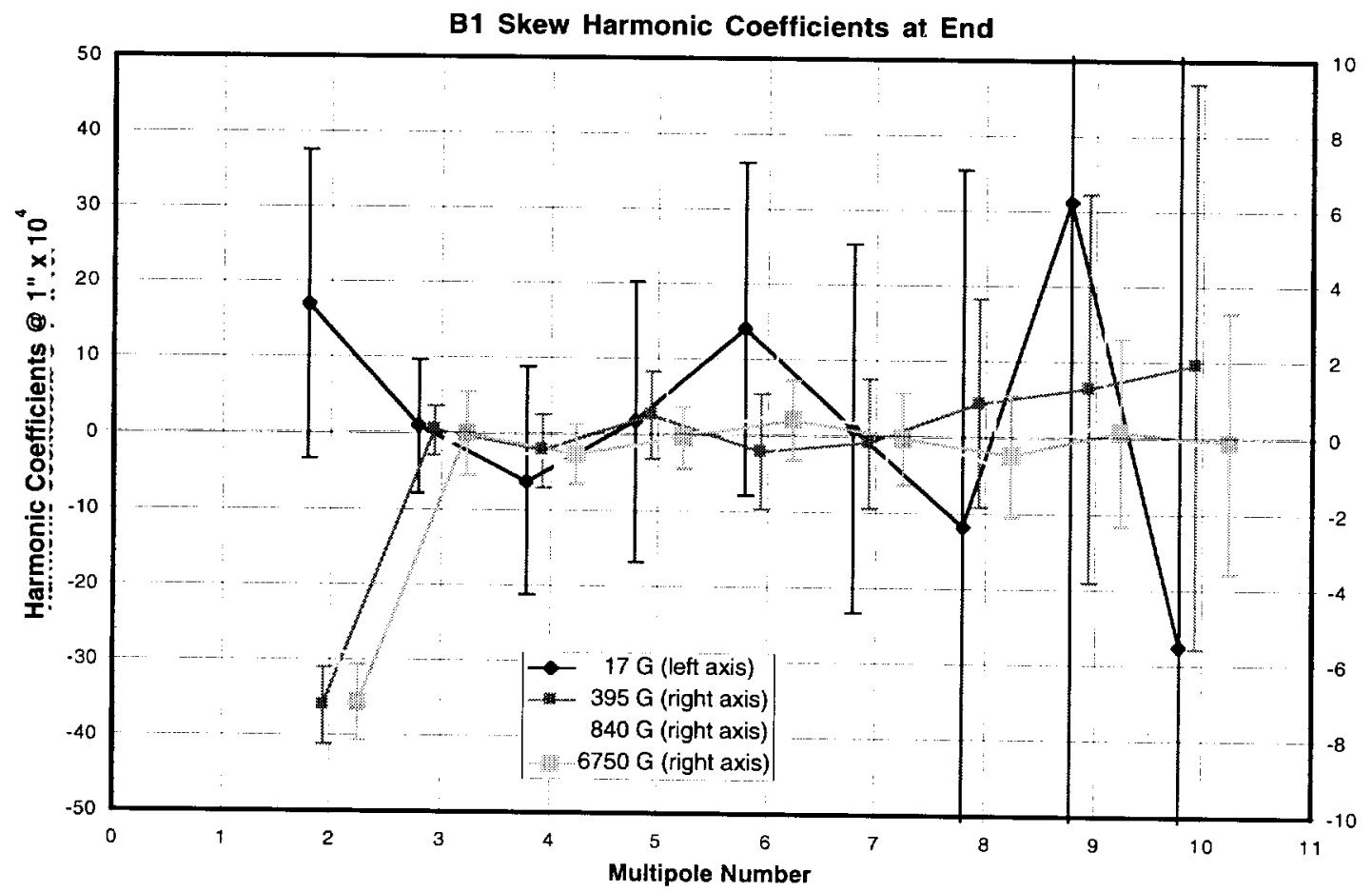

Figure 6. Skew Harmonics at the Ends. 
Fermilab B 1 Magnet Harmonics

Detail Tables

Table 6.1. Harmonic Coefficients at $17 \mathrm{G}$.

\begin{tabular}{|c|c|c|c|c|c|c|c|c|c|c|}
\hline \multirow{3}{*}{ Harmonic } & \multicolumn{5}{|c|}{ Normal } & \multicolumn{5}{|c|}{ Skew } \\
\hline & \multirow[b]{2}{*}{$i$} & \multicolumn{2}{|c|}{ Centerline } & \multicolumn{2}{|c|}{ Edge } & \multirow[b]{2}{*}{$i$} & \multicolumn{2}{|c|}{ Body } & \multicolumn{2}{|c|}{ End } \\
\hline & & $b_{i}$ & $\sigma_{i}$ & $b_{i}$ & $\sigma_{i}$ & & $a_{i}$ & $\sigma_{i}$ & $a_{i}$ & $\sigma_{i}$ \\
\hline Dipole & $b_{i}$ & 1.6 & 68 & 0.8 & 6.4 & $a_{1}$ & -2.4 & 4.7 & -3.2 & 6.0 \\
\hline Quadrupole & $b_{2}$ & 31.4 & 56.5 & -310.1 & 50.2 & $a_{2}$ & 13.7 & 17.5 & 17.1 & 20.5 \\
\hline Sextupole & $b_{3}$ & -197.2 & 23.0 & -109.6 & 21.5 & $a_{3}$ & 0.8 & 8,2 & 1.2 & 8,8 \\
\hline Octupole & $b_{4}$ & -8.5 & 15.8 & 31.2 & 12.1 & $a_{4}$ & -10.8 & 8.8 & -6.1 & 15.2 \\
\hline Decapole & $b_{5}$ & 43.8 & 19.7 & 9.9 & 17.3 & $a_{5}$ & 2.2 & 13.8 & 1.9 & 18.5 \\
\hline Dodecapole & $b_{6}$ & 11.3 & 17.2 & 1.3 & 188 & $a_{6}$ & 12.3 & 18.7 & 14.3 & 22.1 \\
\hline$n=7$ Pole & $b_{7}$ & -26.1 & 30.8 & -13.1 & 25.4 & $a_{7}$ & -0.6 & 22.3 & 1.1 & 24.4 \\
\hline$n=8$ Pole & $b_{8}$ & 3.7 & 47.6 & 146 & 46.8 & $a_{8}$ & -3.3 & 41.5 & -11.6 & 47.2 \\
\hline$n=9$ Pole & $b_{9}$ & 27.8 & 101.6 & 8.0 & 1044 & $a_{9}$ & 5.6 & 84.6 & 31.3 & 124.5 \\
\hline$n=10$ Pole & $b_{10}$ & -364 & 155.1 & -327 & 1516 & $a_{10}$ & 4.2 & 130.5 & -27.5 & 149.7 \\
\hline
\end{tabular}

Table 6.2. Harmonic Coefficients at 395 G.

\begin{tabular}{|c|c|c|c|c|c|c|c|c|c|c|}
\hline \multirow{3}{*}{ Harmonic } & \multicolumn{5}{|c|}{ Normal } & \multicolumn{5}{|c|}{ Skew } \\
\hline & \multirow[b]{2}{*}{$i$} & \multicolumn{2}{|c|}{ Centerline } & \multicolumn{2}{|c|}{ Edge } & \multirow[b]{2}{*}{$i$} & \multicolumn{2}{|c|}{ Body } & \multicolumn{2}{|c|}{ End } \\
\hline & & $b_{i}$ & $\sigma_{i}$ & $b_{i}$ & $\sigma_{i}$ & & $a_{i}$ & $\sigma_{i}$ & $a_{i}$ & $\sigma_{i}$ \\
\hline Dipole & $b_{1}$ & 1.1.2 & 2.6 & -1.1 & 2.3 & $a_{1}$ & -0.7 & 1.3 & $-0,1$ & 37 \\
\hline Quadrupole & $b_{2}$ & 1.3 & 1.9 & -10.1 & 2.3 & $a_{2}$ & 0.8 & 0.9 & $\sqrt{7.2}$ & 17 \\
\hline Sextupole & $b_{3}$ & -8.0 & 1.6 & -3.0 & 1.2 & $a_{3}$ & 0,0 & 0.8 & 0,0 & 1.2 \\
\hline Octupole & $b_{4}$ & -0.9 & 1.5 & 1.0 & 1.4 & $a_{4}$ & -0.3 & 0.9 & 0.7 & 1,1 \\
\hline Decapole & $b_{5}$ & 4.2 & 2.5 & 0.6 & 1.1 & $a_{5}$ & 00 & 1.0 & 0.3. & 1.4 \\
\hline Dodecapole & $b_{6}$ & 1.7 & 2.1 & 0.1 & 1.7 & $a_{6}$ & 1.0 & 1.6 & 1.1 & 1.7 \\
\hline$n=7$ Pole & $b_{7}$ & -4.0 & 3.1 & -1.1 & 23 & $a_{7}$ & 0.1 & 1.6 & 00 & 1.8 \\
\hline$n=8$ Pole & $b_{8}$ & -1.3 & 3.7 & 0.4 & 3.1 & $a_{8}$ & 0.7 & 30 & .0 .4 & 30 \\
\hline$n=9$ Pole & $b_{9}$ & 4.0 & 5.7 & 0.4 & 5.2 & $a_{9}$ & 0.6 & 4.7 & 0.6 & 5.5 \\
\hline$n=10$ Pole & $b_{10}$ & 0.8 & 8.3 & -1.1 & 8.2 & $a_{10}$ & 0.6 & 7,0 & .0 .7 & 7.8 \\
\hline
\end{tabular}


Fermilab B1 Magnet Harmonics

Table 6.3. Harmonic Coefficients at $840 \mathrm{G}$.

\begin{tabular}{|c|c|c|c|c|c|c|c|c|c|c|}
\hline \multirow{3}{*}{ Harmonic } & \multicolumn{5}{|c|}{ Normal } & \multicolumn{5}{|c|}{ Skew } \\
\hline & \multirow[b]{2}{*}{$i$} & \multicolumn{2}{|c|}{ Centerline } & \multicolumn{2}{|c|}{ Edge } & \multirow[b]{2}{*}{$i$} & \multicolumn{2}{|c|}{ Body } & \multicolumn{2}{|c|}{ End } \\
\hline & & $b_{i}$ & $\sigma_{i}$ & $b_{i}$ & $\sigma_{i}$ & & $a_{i}$ & $\sigma_{i}$ & $a_{i}$ & $\sigma_{i}$ \\
\hline Dipole & $b_{1}$ & -10 & 2.6 & -1.2 & 2.4 & $a_{1}$ & -0.6 & 1.3 & 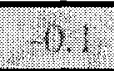 & 3.6 \\
\hline Quadrupole & $b_{2}$ & 0.7 & 0.8 & -3.9 & 1.8 & $a_{2}$ & 0.4 & 0.9 & $\mid-7.1$ & $\sqrt{1.3}$ \\
\hline Sextupole & $b_{3}$ & -3.9 & 1.4 & -0.6 & 1.7 & $a_{3}$ & 0.1 & 1.1 & 0.0 & 1.3 \\
\hline Octupole & $b_{4}$ & -0.7 & 1.2 & 0.2 & 14 & $a_{4}$ & 02 & 24 & 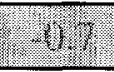 & 3 \\
\hline Decapole & $b_{5}$ & 3.2 & 2.3 & 0.2 & 3.9 & $a_{5}$ & .0 .1 & 2.1 & 0.1 & 1.9 \\
\hline Dodecapole & $b_{6}$ & 1.4 & 1.9 & 0.5 & 4.1 & $a_{6}$ & 0.6 & 3.4 & 0.6 & 2.1 \\
\hline$n=7$ Pole & $b_{7}$ & -3.5 & 3.1 & -1.3 & 2.5 & $a_{7}$ & 0.5 & 50 & 0,3 & 3,8 \\
\hline$n=8$ Pole & $b_{8}$ & -1.3 & 3.2 & 00 & 53 & $a_{8}$ & -1.0 & 49 & 47 & 3.8 \\
\hline$n=9$ Pole & $b_{9}$ & 3.0 & 4.4 & 1.2 & 8.0 & $a_{9}$ & 0.4 & 4.4 & 0.4 & 41 \\
\hline$n=10$ Pole & $b_{10}$ & -0.2 & 6.1 & .1 .6 & 6.3 & $a_{10}$ & 0.4 & 100 & -10.2 & 8.1 \\
\hline
\end{tabular}

Table 6.4. Harmonic Coefficients at $6750 \mathrm{G}$.

\begin{tabular}{|c|c|c|c|c|c|c|c|c|c|c|}
\hline \multirow{3}{*}{ Harmonic } & \multicolumn{5}{|c|}{ Normal } & \multicolumn{5}{|c|}{ Skew } \\
\hline & \multirow[b]{2}{*}{$i$} & \multicolumn{2}{|c|}{ Centerline } & \multicolumn{2}{|c|}{ Edge } & \multirow[b]{2}{*}{$i$} & \multicolumn{2}{|c|}{ Body } & \multicolumn{2}{|c|}{ End } \\
\hline & & $b_{i}$ & $\sigma_{i}$ & $b_{i}$ & $\sigma_{i}$ & & $a_{i}$ & $\sigma_{i}$ & $a_{i}$ & $\sigma_{i}$ \\
\hline Dipole & $b_{1}$ & 1.1 & 20 & -1.2 & 2.2 & $a_{1}$ & -0.6 & 1.1 & (j) & 3.8 \\
\hline Quadrupole & $b_{2}$ & 0.3 & 0.4 & $-0,2$ & 1.6 & $a_{2}$ & 0.3 & 0.6 & -7.1 & 1.0 \\
\hline Sextupole & $b_{3}$ & -1.5 & 1.4 & 0.2 & 0.8 & $a_{3}$ & 0,0 & 0.7 & 0,0 & 1.1 \\
\hline Octupole & $b_{4}$ & -0.7 & 0.9 & -0.1 & 1.0 & $a_{4}$ & 0.1 & 0.7 & -0.5 & 0.8 \\
\hline Decapole & $b_{5}$ & 2.6 & 2.2 & 0.3 & 0.6 & $a_{5}$ & 0.1 & 0.6 & 00 & 0,8 \\
\hline Dodecapole & $b_{6}$ & 1.3 & 1.8 & 0.1 & 1.1 & $a_{6}$ & 0.5 & 1.1 & 0.5 & 1.1 \\
\hline$n=7$ Pole & $b_{7}$ & -3.3 & 2.8 & -0.7 & 1.4 & $a_{7}$ & 0,0 & 1.2 & 0,0 & 1.2 \\
\hline$n=8$ Pole & $b_{8}$ & -1.4 & 2.7 & 0.6 & 1.7 & $a_{8}$ & .03 & 1.9 & -0.5 & 1.6 \\
\hline$n=9$ Pole & $b_{9}$ & 3.4 & 3.7 & 0.2 & 26 & $a_{9}$ & 0.1 & 2.0 & 0,2 & 25 \\
\hline$n=10$ Pole & $b_{10}$ & 09 & 47 & -1.2 & 3.7 & $a_{10}$ & 64 & 3.6 & 01 & 35 \\
\hline
\end{tabular}


Fermilab B1 Magnet Harmonics

Detail Figures

B1 Normal Harmonics @ 17 G (Remanent)

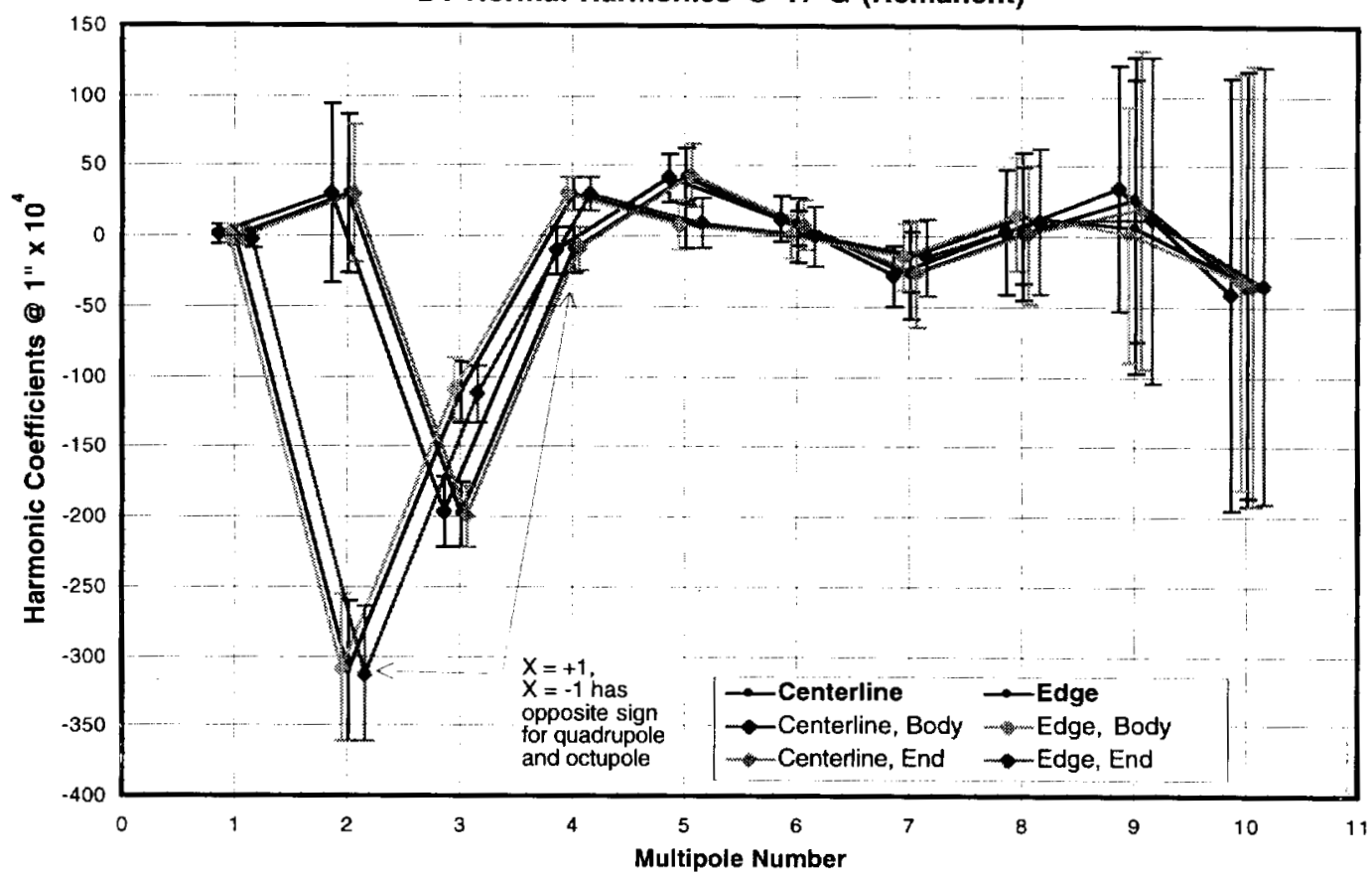

Figure 7. Normal Harmonics at $17 \mathrm{G}$.

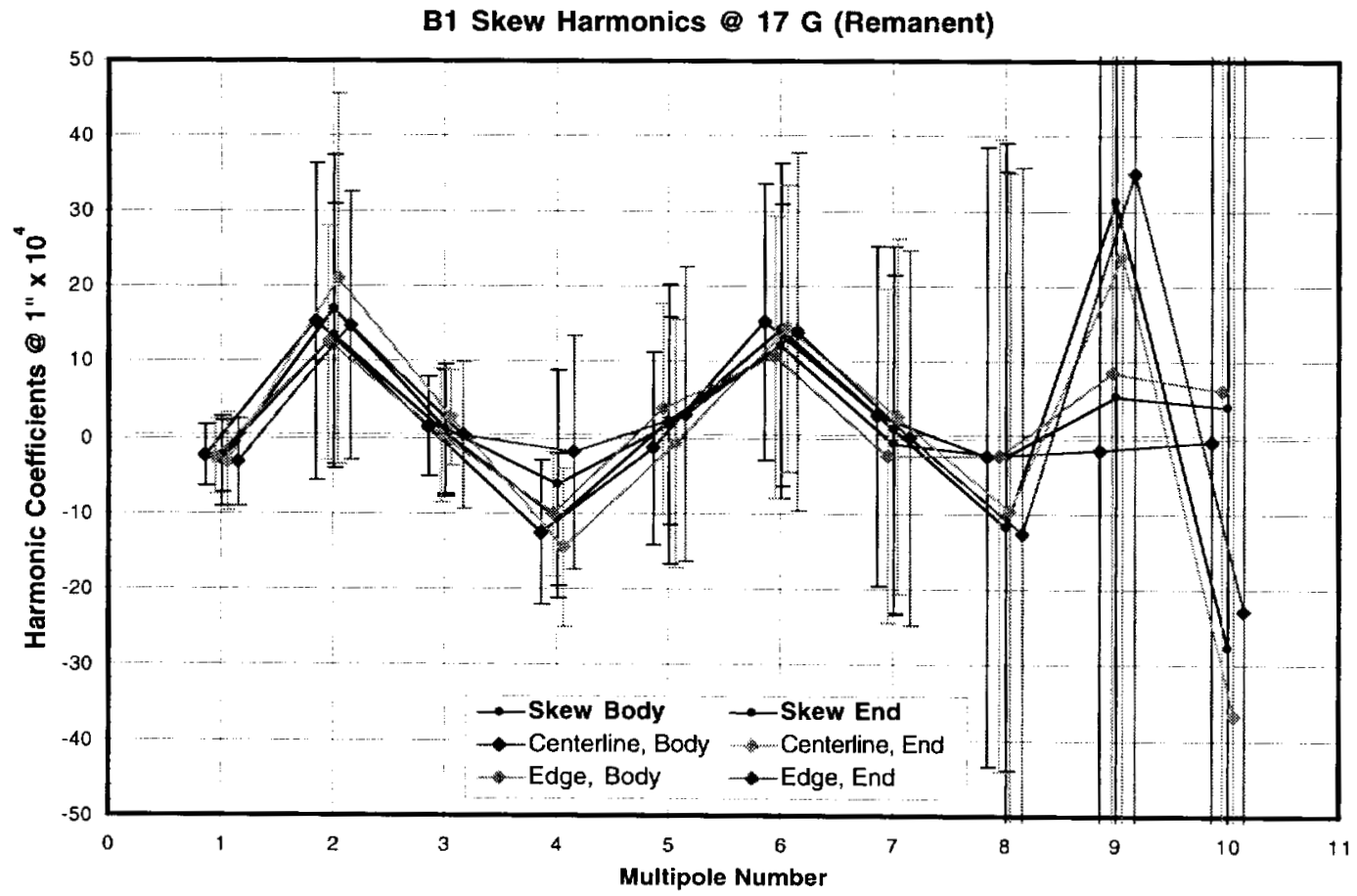

Figure 8. Skew Harmonics at $17 \mathrm{G}$. 


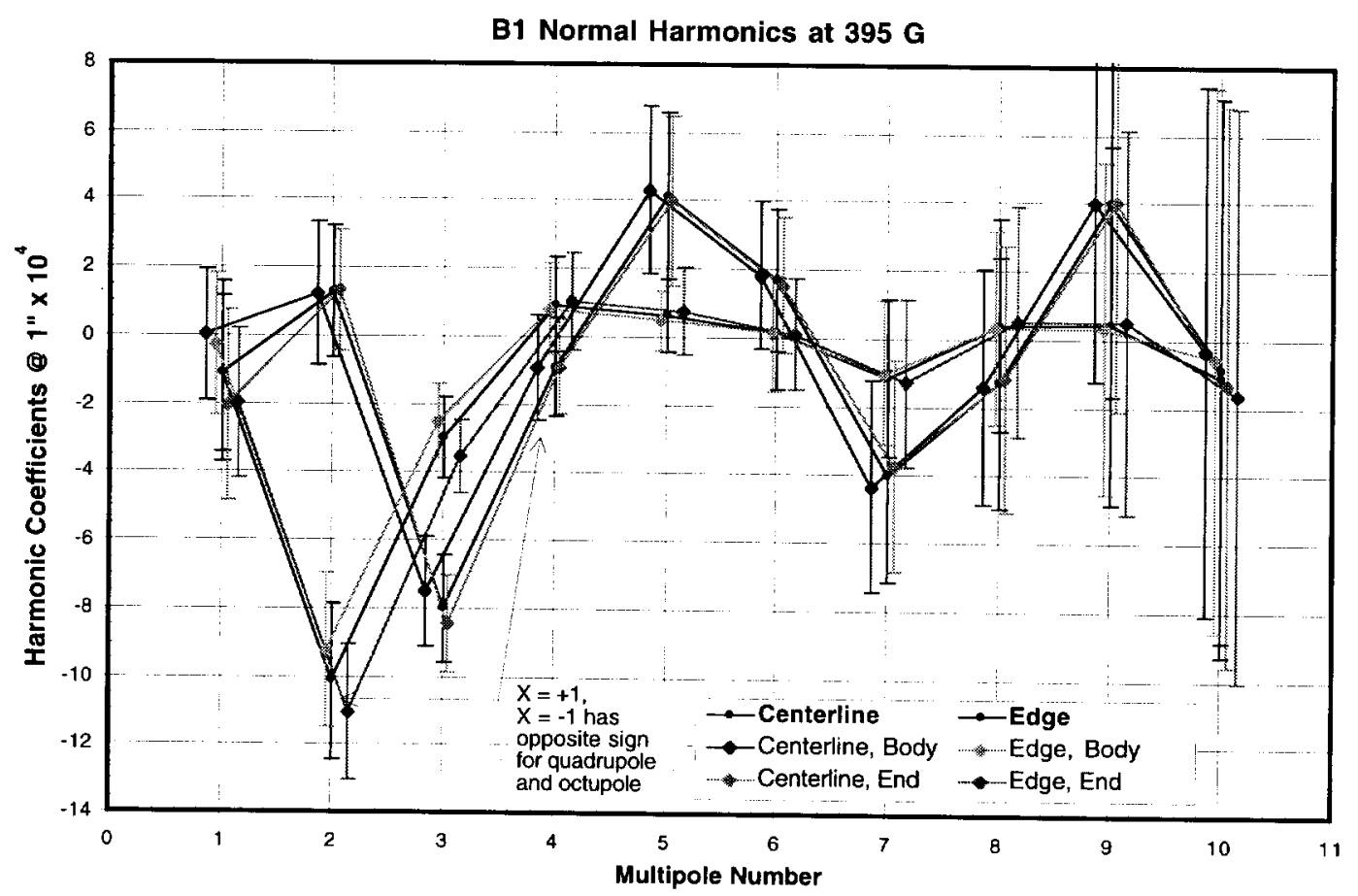

Figure 9. Normal Harmonics at 395 G.

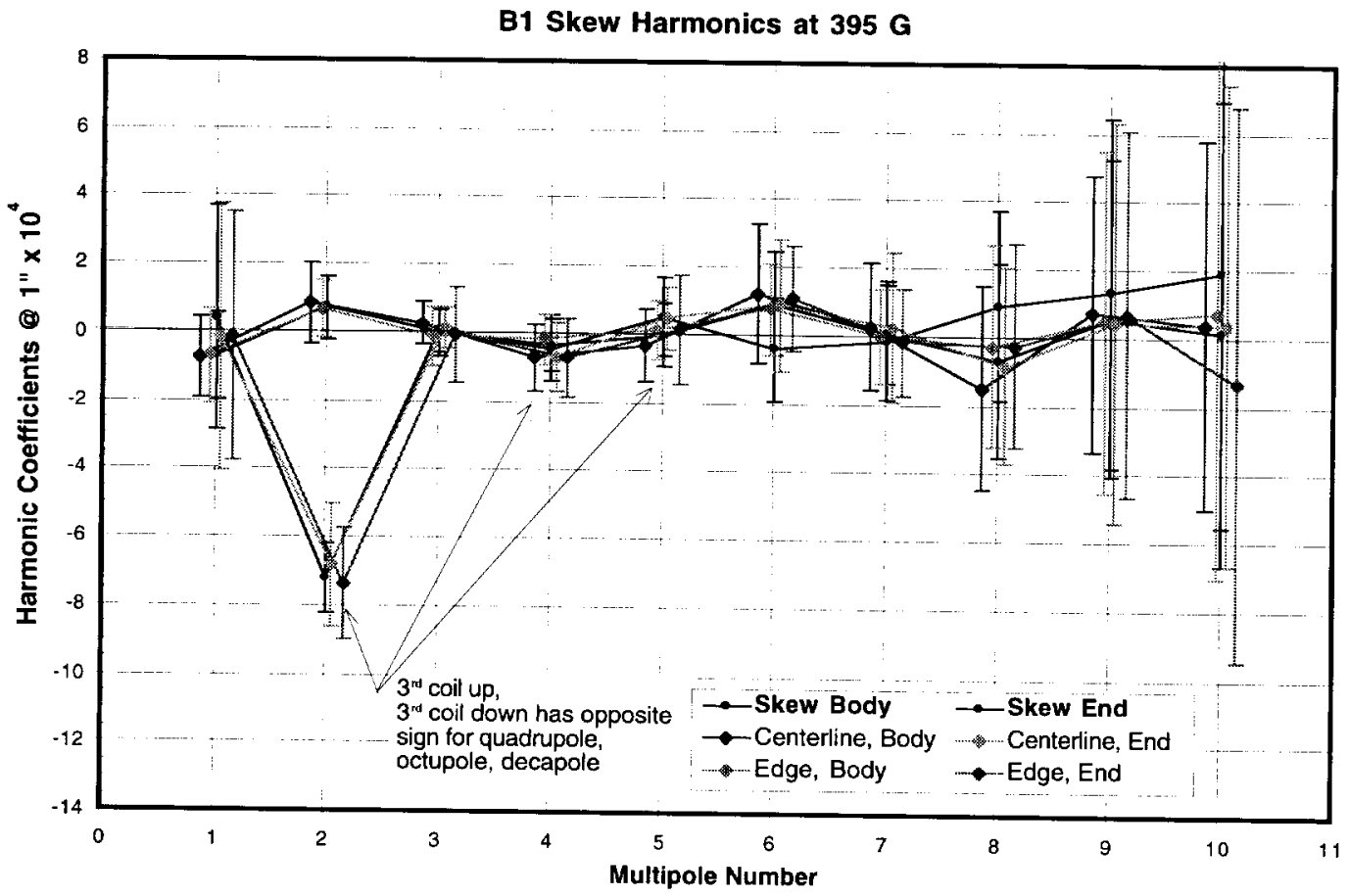

Figure 10. Skew Harmonics at 395 G. 


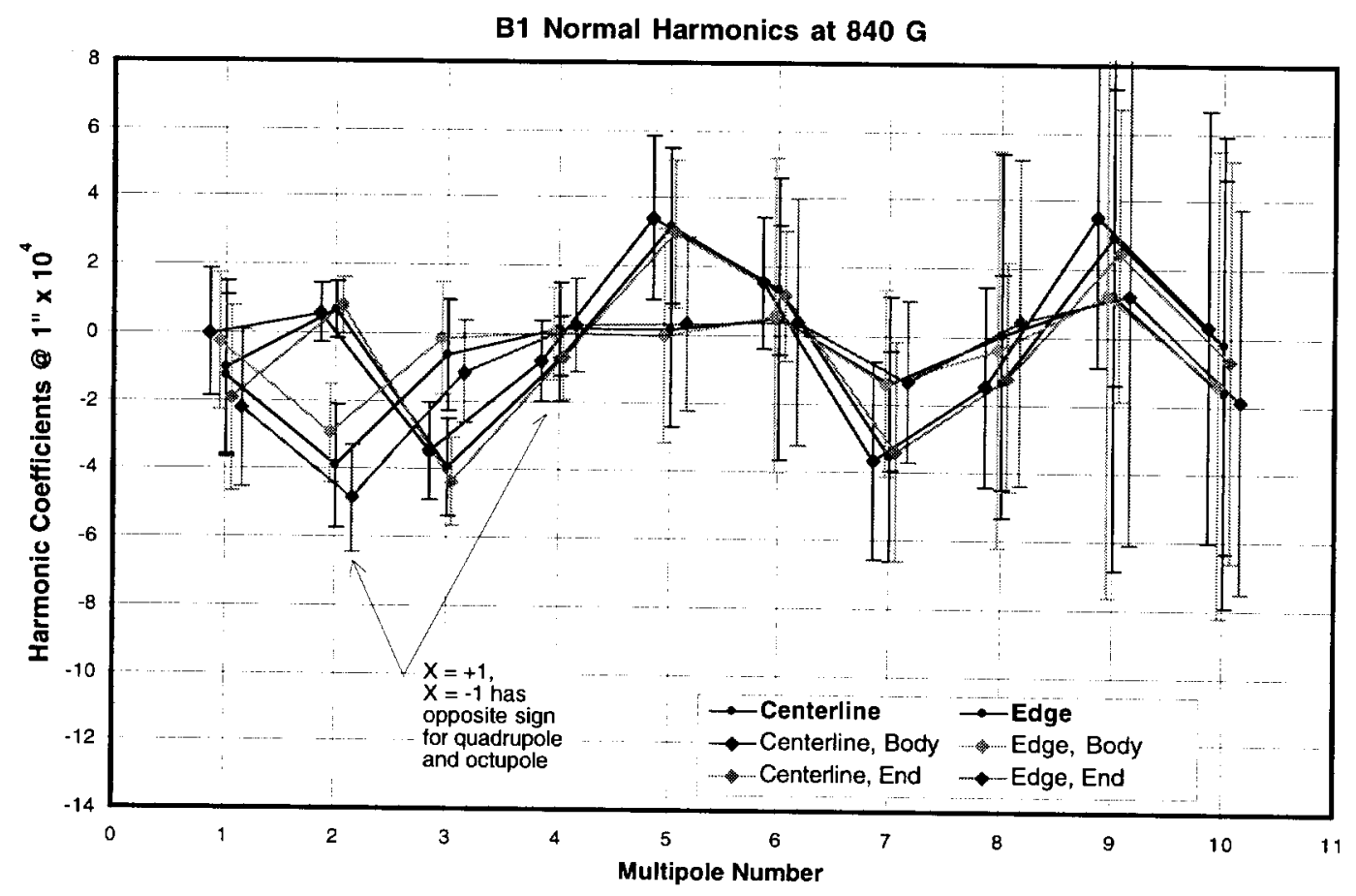

Figure 11. Normal Harmonics at $840 \mathrm{G}$.

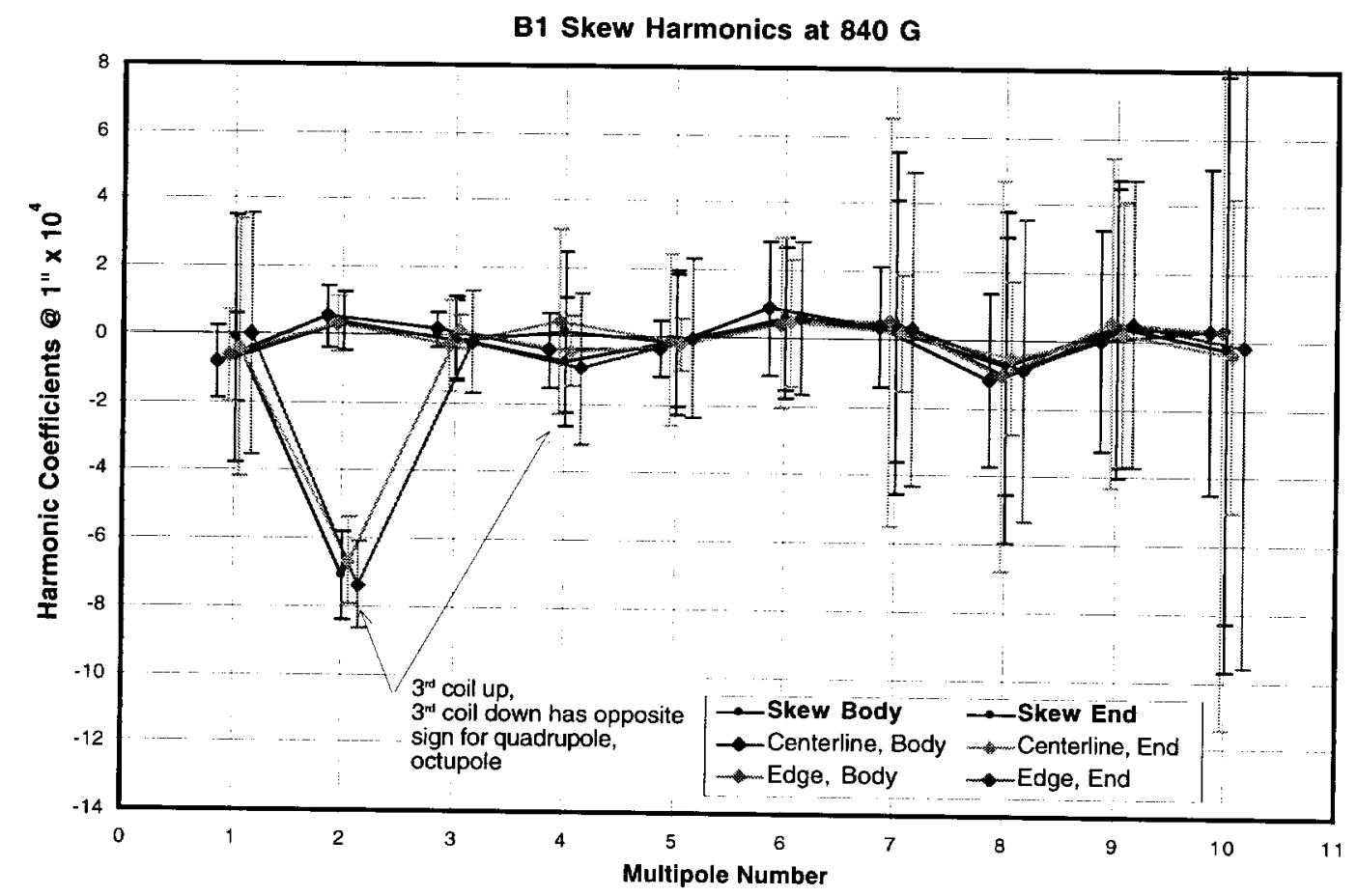

Figure 12. Skew Harmonics at $840 \mathrm{G}$. 


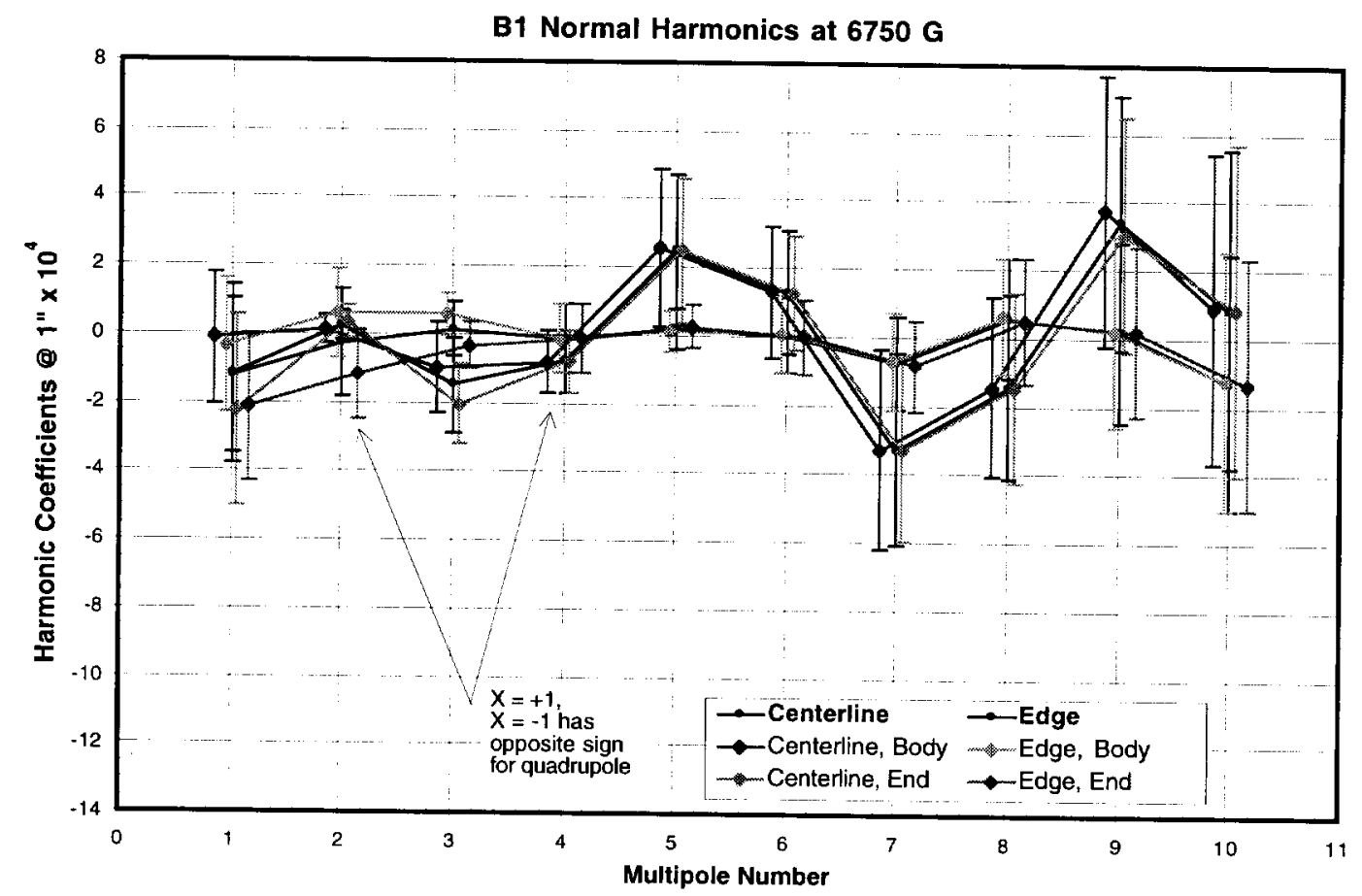

Figure 13. Normal Harmonics at $6750 \mathrm{G}$.

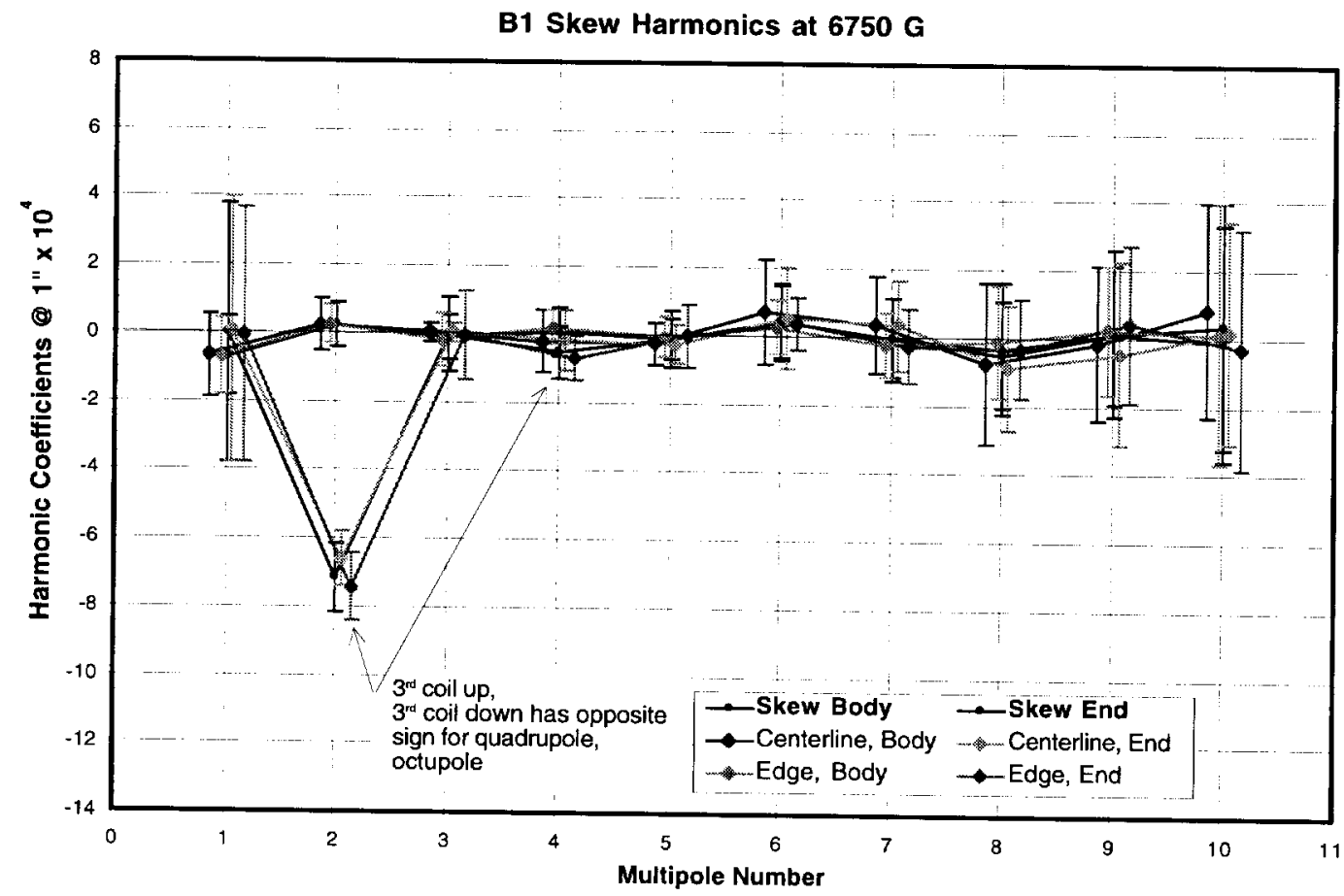

Figure 14. Skew Harmonics at $6750 \mathrm{G}$. 
Fermilab B1 Magnet Harmonics

\section{Individual Harmonics}

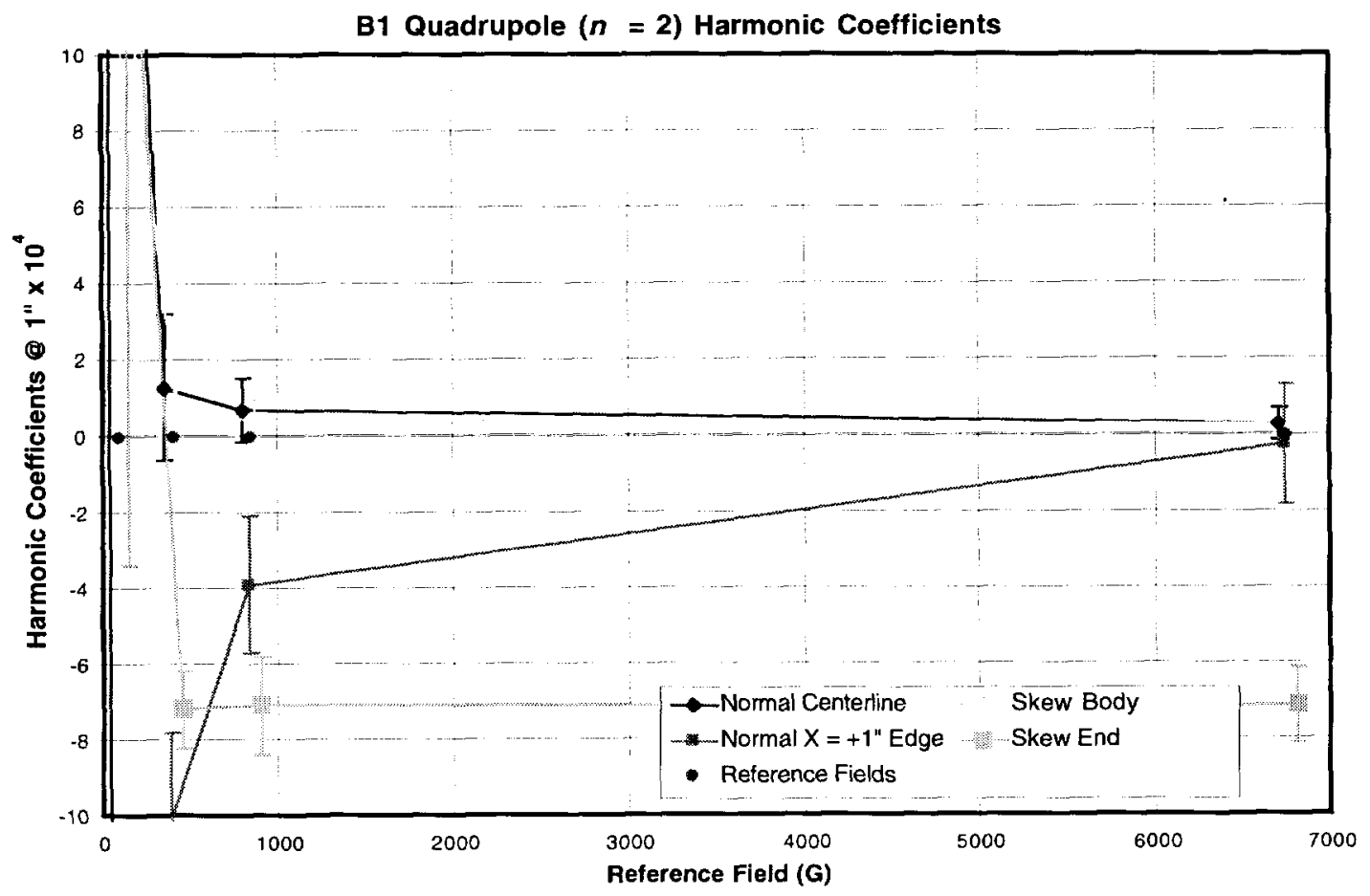

Figure 15. Quadrupole $(n=2)$ Harmonics.

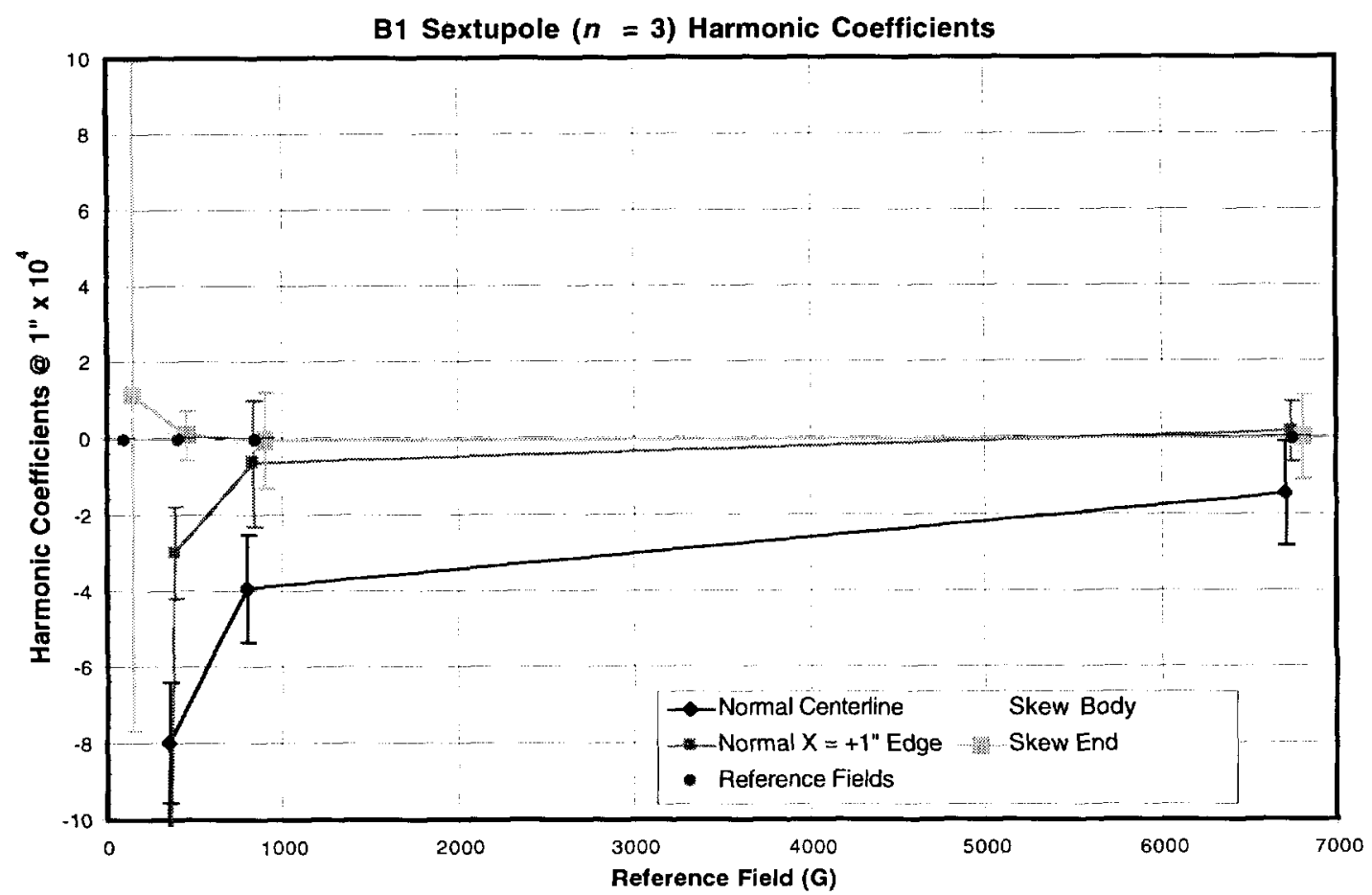

Figure 16. Sextupole $(n=3)$ Harmonics. 
B1 Octupole $(n=4)$ Harmonic Coefficients

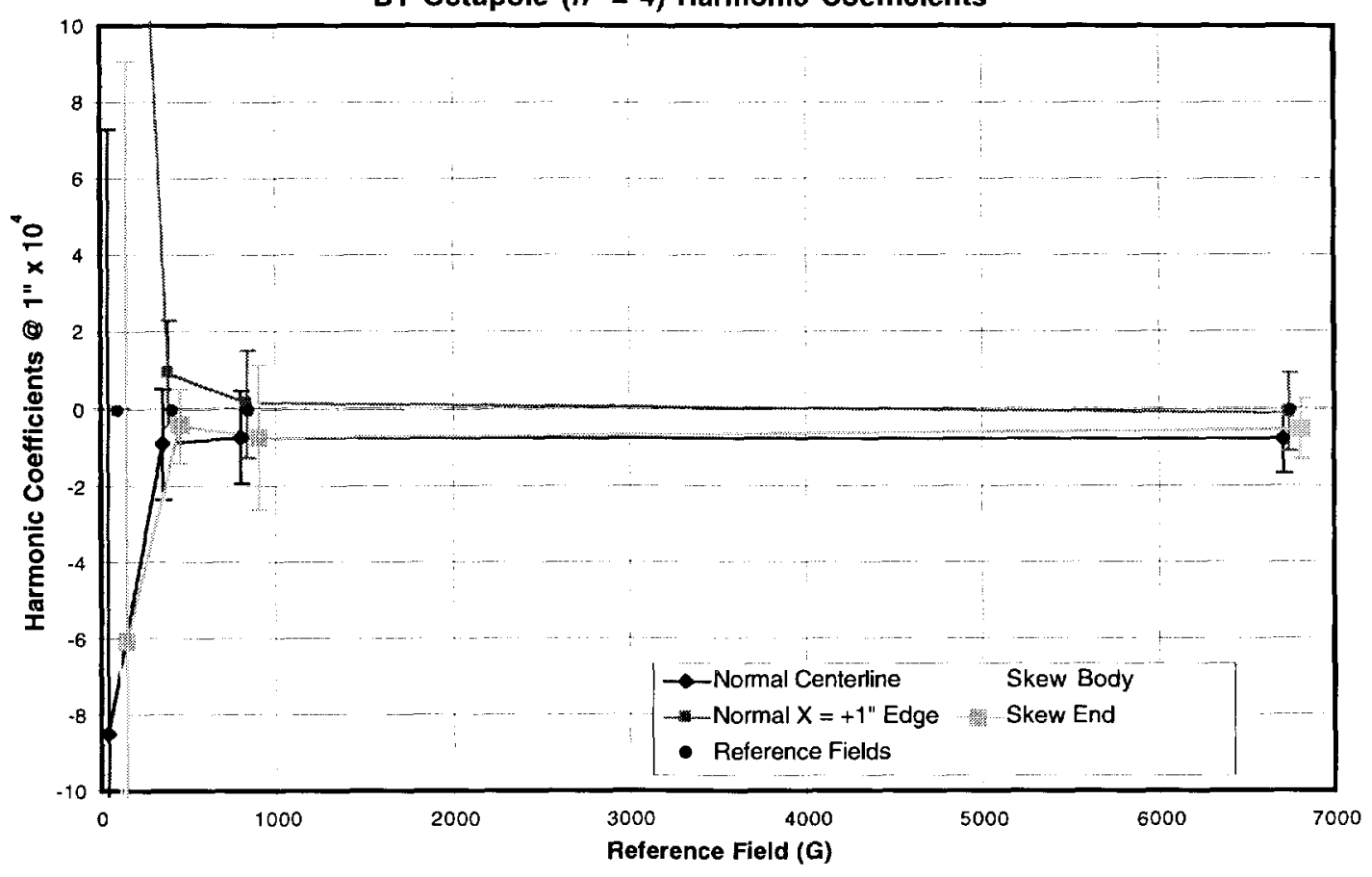

Figure 17. Octupole $(n=4)$ Harmonics.

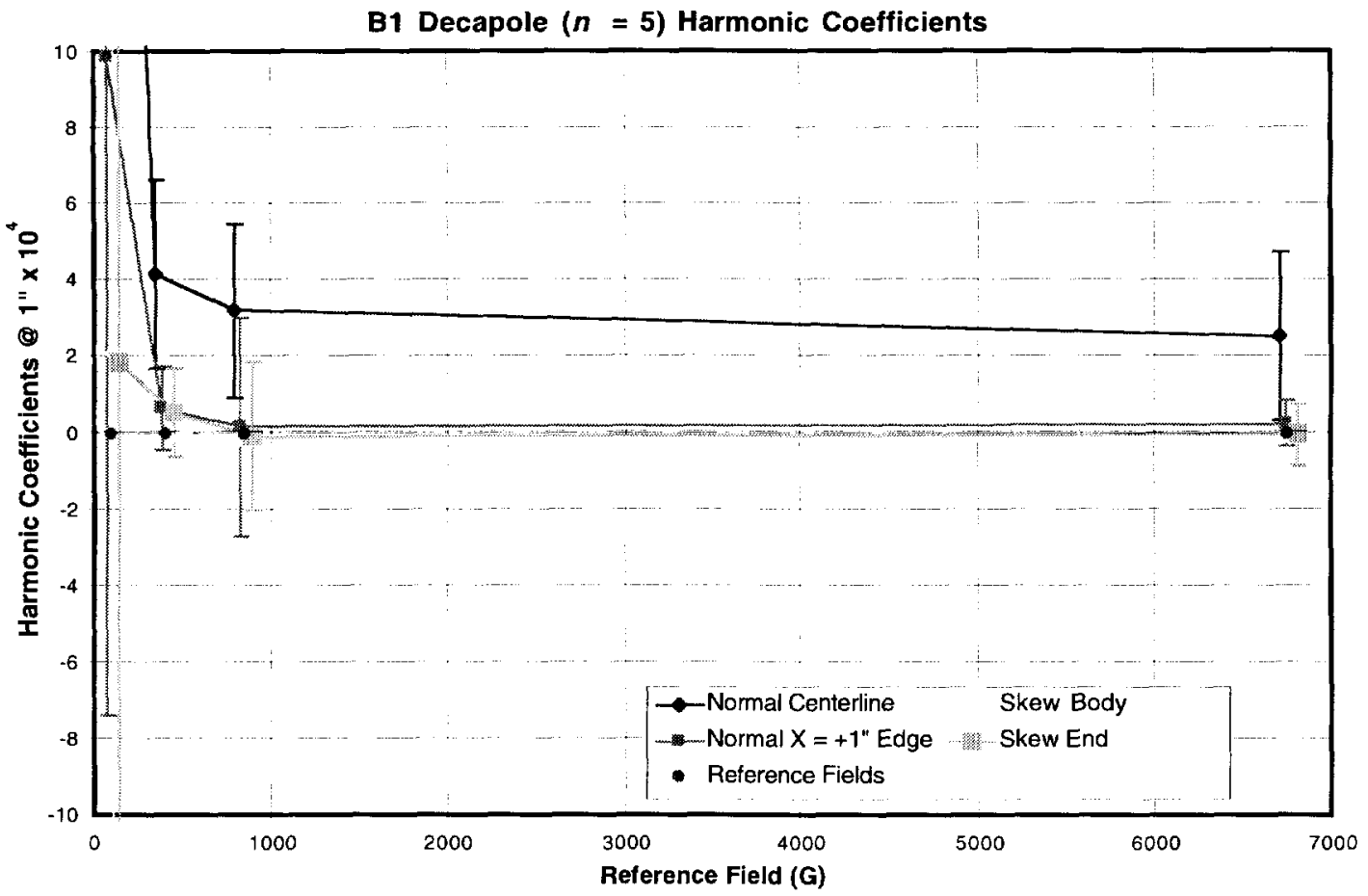

Figure 18. Decapole $(n=5)$ Harmonics. 
Fermilab B1 Magnet Harmonics

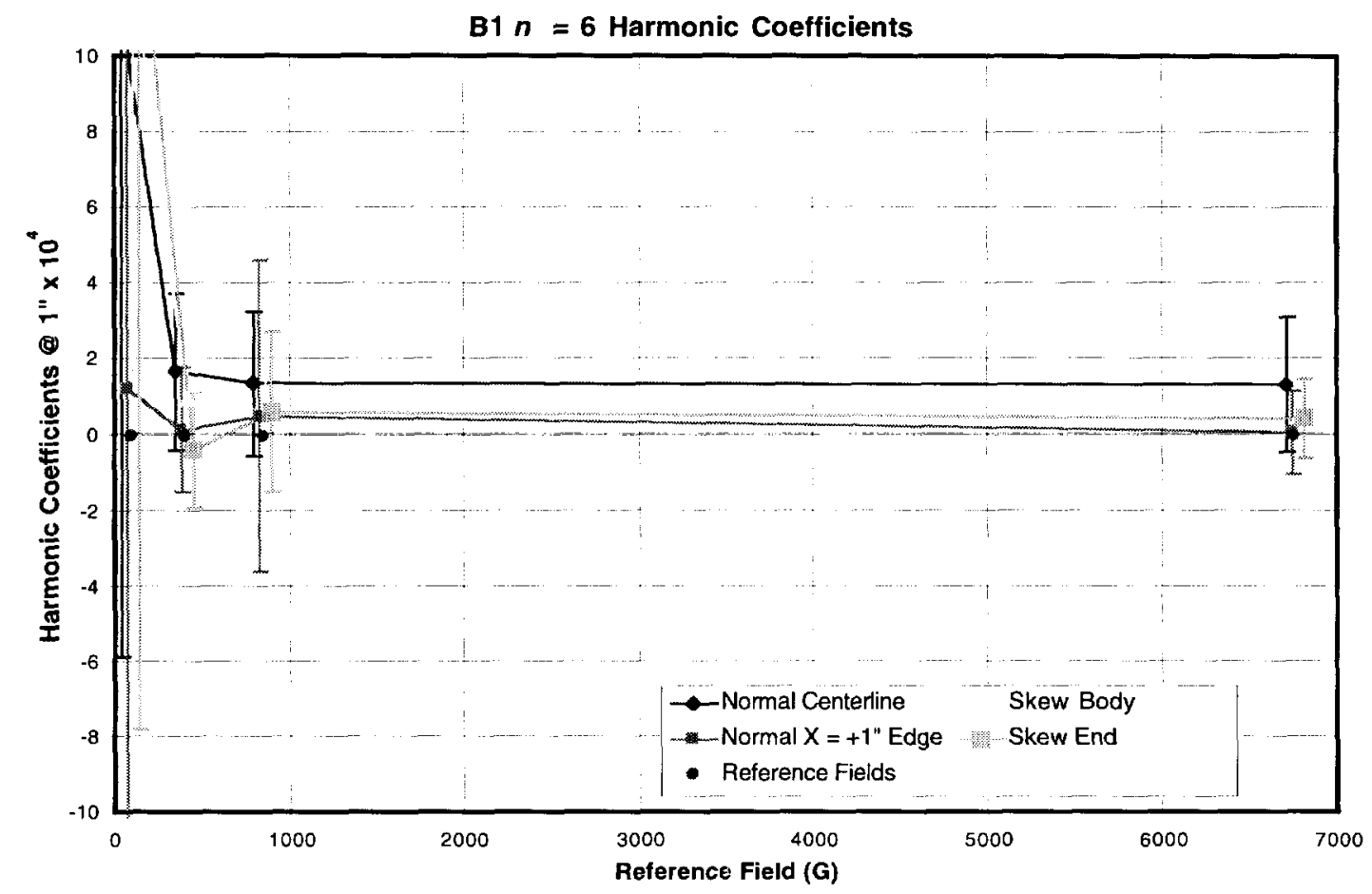

Figure 19. Dodecapole $(n=6)$ Harmonics.

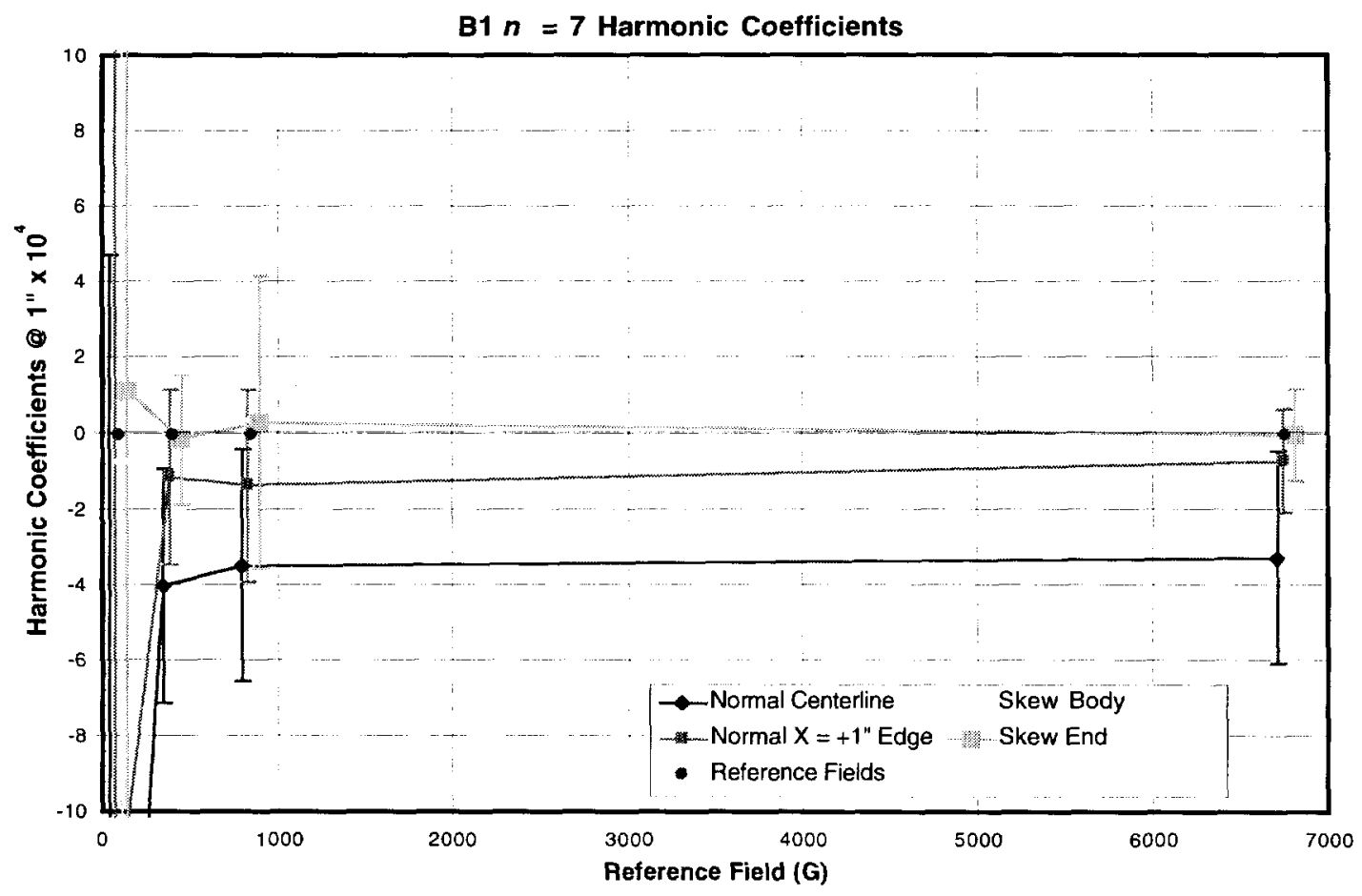

Figure 20. $n=7$ Harmonics. 
Fermilab B1 Magnet Harmonics

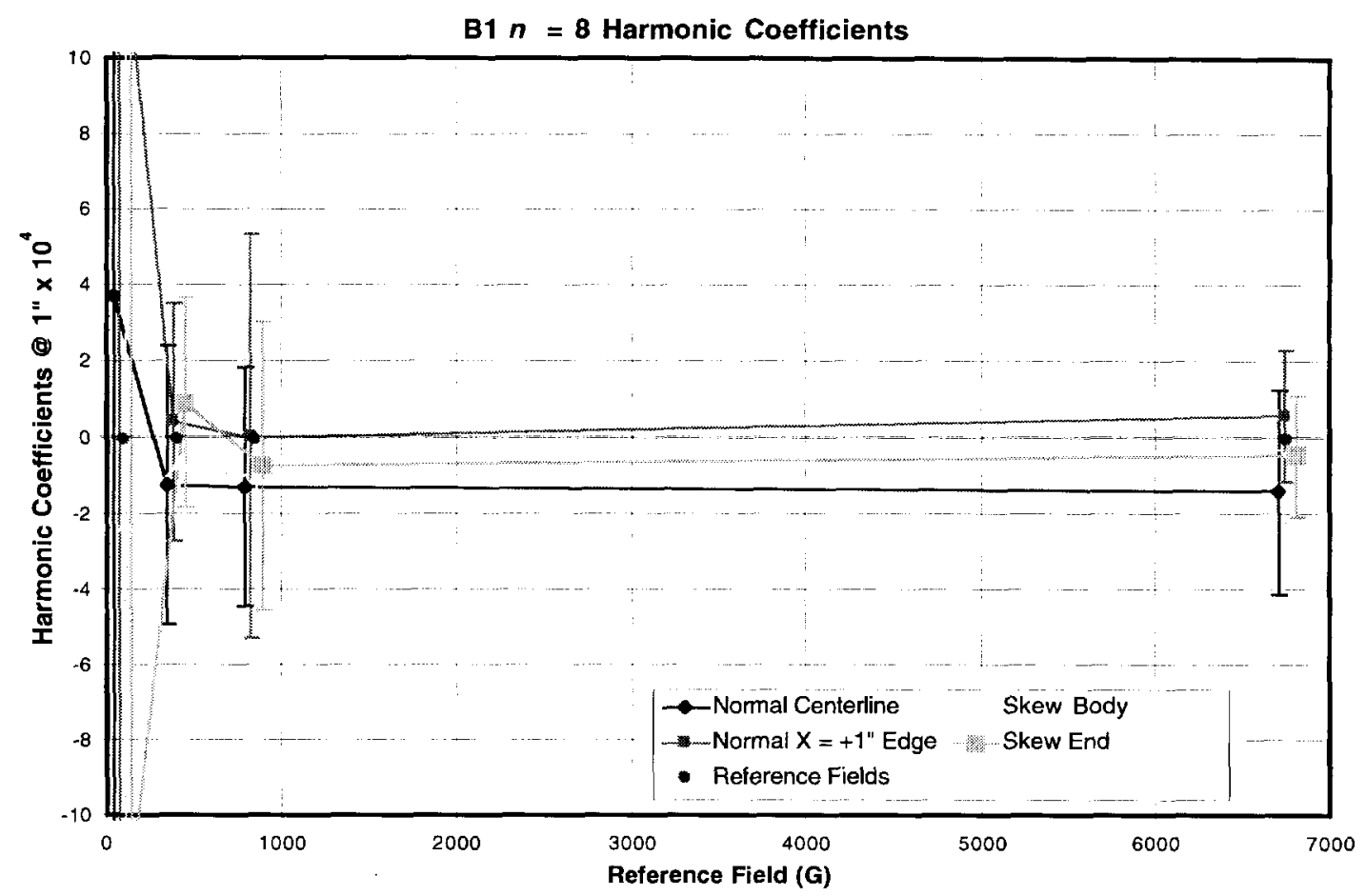

Figure 21. $n=8$ Harmonics.

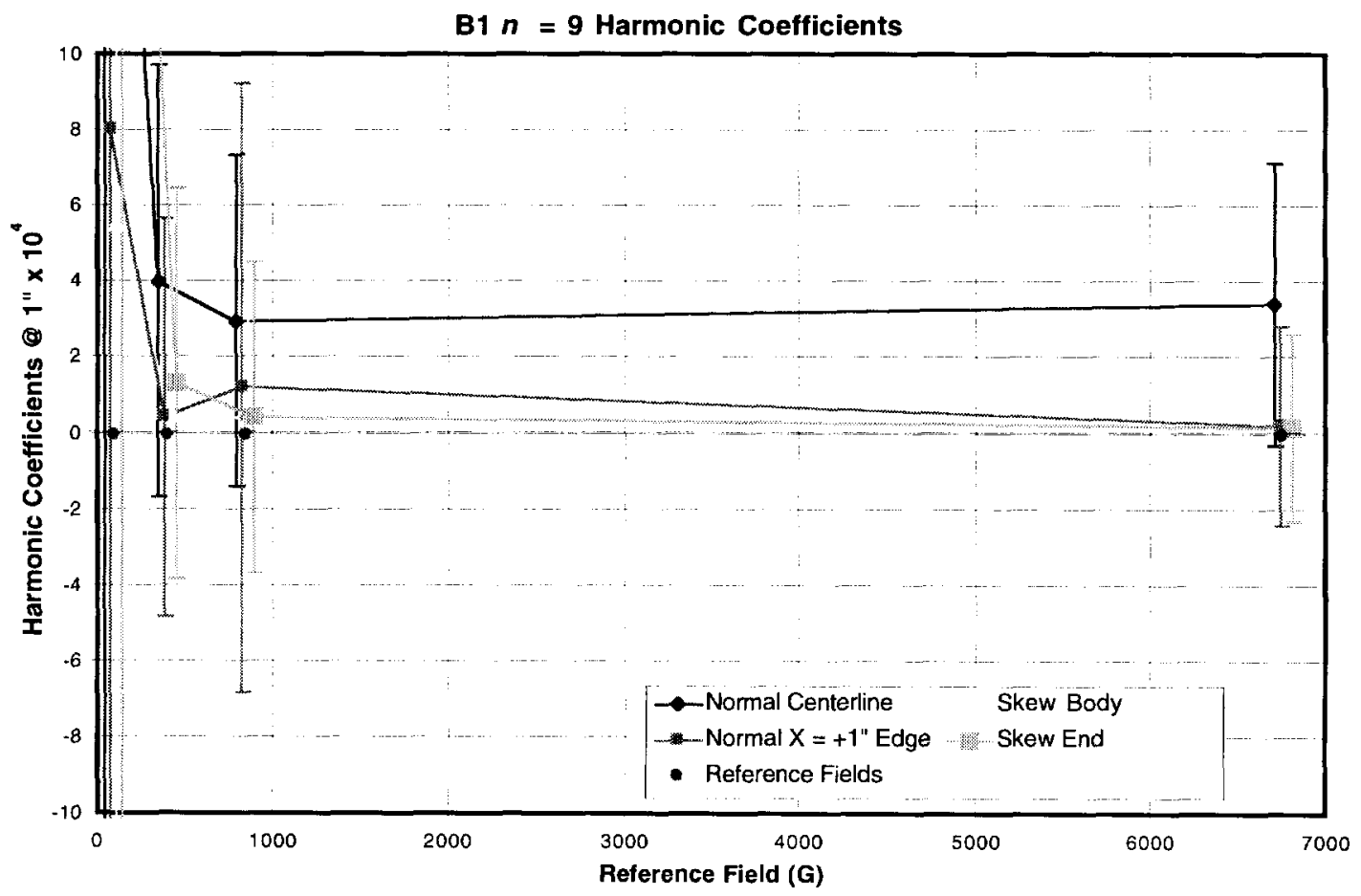

Figure 22. $n=9$ Harmonics. 


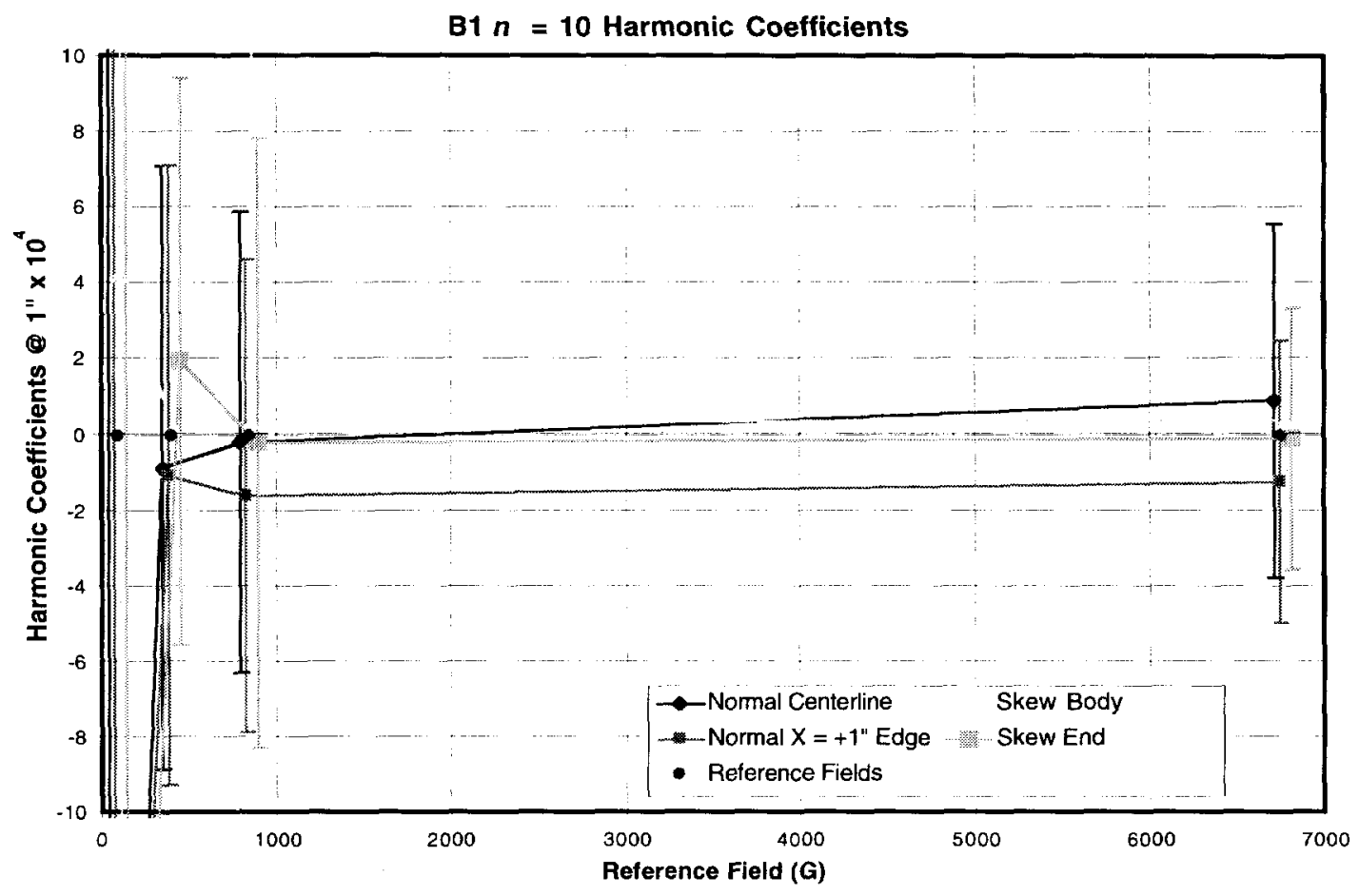

Figure 23. $n=10$ Harmonics.

\section{Discussion of Results}

A few points are worth noting. For harmonics with $n \leq 6$ the widths of the distributions are essentially the same, about \pm 2 units, except for the remnant harmonics. For $n>6$ the widths appear to increase rapidly. However, according to Bruce Brown and Dave Harding, this is likely due to electronics noise, so these widths should be considered unreliable in that they overestimate the real variations from magnet to magnet.

The uncertainty on the mean value for any harmonic coefficient is much less than the r.m.s. width for the coefficient, because of the large number of magnets and individual measurements that are included. If the coefficients for a given magnet are highly correlated, then there are effectively 32 separate measurements (one per magnet) included for each final coefficient. If the coefficients for different probe locations in the same magnet are uncorrelated, then the number of measurements given in the Analysis Parameters table should be used. (I will discuss correlations of errors in a subsequent note.) The errors on the means, $\sigma / \sqrt{N}$, are at most $1 / 5$ and as little as $1 / 13$ of the r.m.s. widths, or in the range $0.15-0.4$ units for $n \leq 6$. For $n>6$, the error on the means could be in the range $0.5-1$ units. Therefore, the systematic multipoles with $n>6$ are probably real, though the width of the distribution is undetermined. 
According to Bruce Brown and Dave Harding, the probe is known to suffer from a "deadly skew quad" effect, which results in a large spurious skew quadrupole in the measurement.[11] It is apparently a capacitive coupling to the environment, particularly the asymmetric beam pipe, since wrapping the probe in a grounded conducting layer greatly diminishes the effect. The wrapping does not completely eliminate it, however, and the residual impact is unknown. This uncertainty is a major reason why Bruce and Dave have not published these measurements. (However, some results were reported indirectly, see the next section.) This effect calls into question the reliability of the skew quadrupole coefficients shown here.

\section{Historical Comparison}

Harmonic measurements have been made on the Main Ring magnets (at least) three times, during the initial production (prior to 1972), in 1975, and again in the late 1980's, the measurements analyzed here.

The measurements made during the initial production were reported by A. G. Ruggiero in TM-474 in 1974.[12] His sample included 348 B1's built and measured before September 1972 . The measurements were made with a flat coil probe on centerline and at $\pm 1 "$ and \pm 2 ". He reported only the quadrupole and sextupole normal harmonics on the centerline. The source data has subsequently been lost.[13-15] (The measurements at $\pm 2 "$ would be particularly interesting for the Scrounge-atron.)

In 1975, B. A. Prichard, Jr., measured several magnets from the "transfer hall magnet cage." These were reported in TM-543.[16] He was interested in remnant fields and the effect of the ramp cycle. These magnets had experienced the same ramping history as the magnets in the ring, important for understanding the remnants in the ring. Measurements were made at $z=20^{\prime \prime}, 23 ", 24 "$ (measured from the aperture face, $+z$ going into the magnet), in $0.1 "$ steps in $x$, using a Rawson probe. As before, he reported only normal centerline quadrupole and sextupole coefficients. To explore the effect of the ramp on the remnant field, he made measurements after ramps to 100,300 , or $400 \mathrm{GeV}$ field levels, then turned off the supply during the front porch to reach the remnant condition. He also modified the down ramp by tripping the magnet off during the flat top and letting the current decay. This resulted in a reduction of the sextupole component by $13 \%$.

Finally, results from the original analysis of the data discussed here were reported in summary form by R. Gerig, et al. in a conference paper on modeling the Main Ring.[17]

These three historical analyses, along with the current analysis, are plotted in Figures 24-25. For the normal harmonics, only the centerline results are shown, since the prior work focused on the centerline volume sampled by the beam in the Main Ring. For the skew harmonics, both the body and end spectra resulting from this analysis are shown, along with the skew harmonics reported by Gerig, et al. The comparison should be made between the Gerig, et al. results and the average of the two skew harmonic spectra resulting from the analysis reported here. 


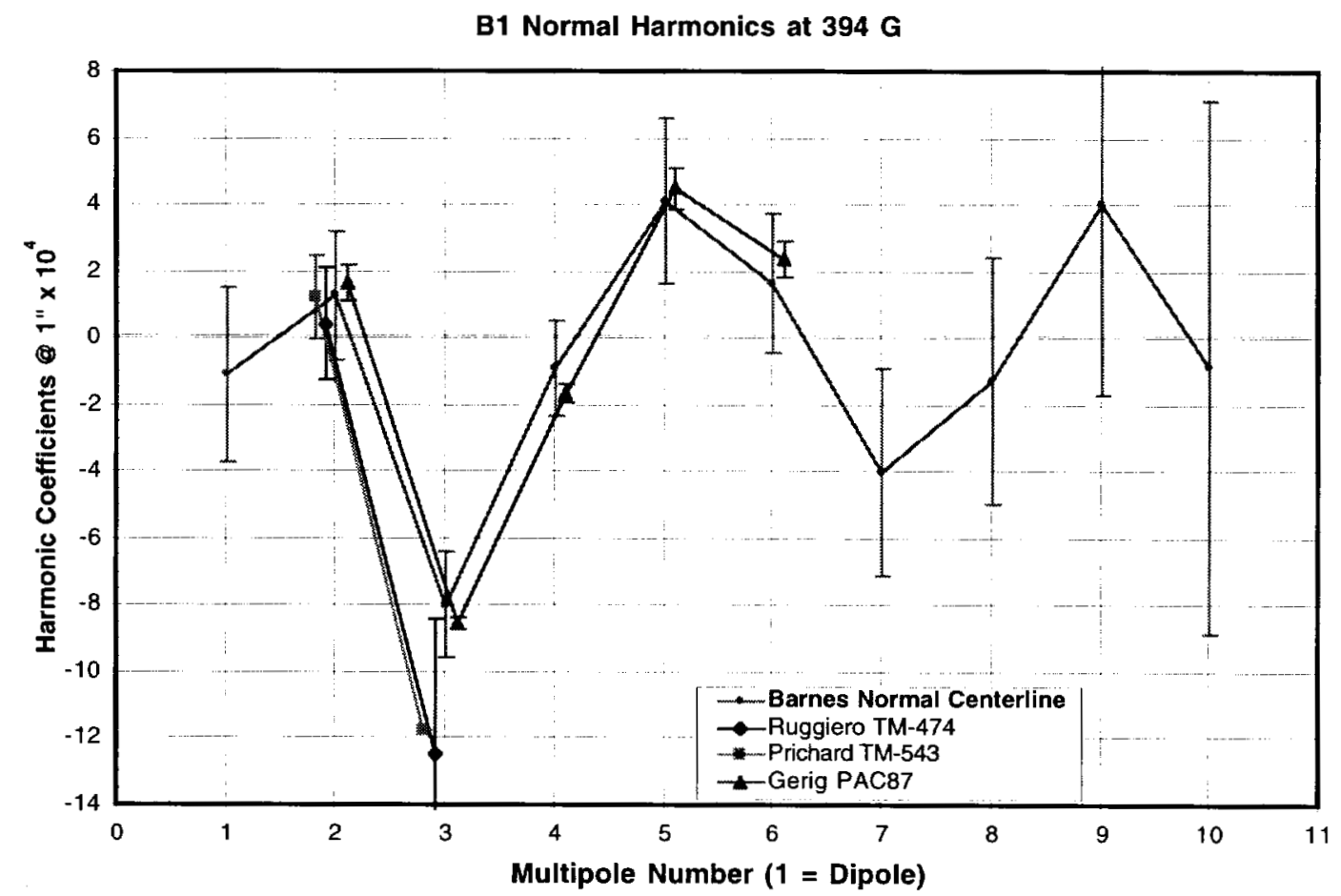

Figure 24. Historical Data for Normal Harmonics on the Centerline.

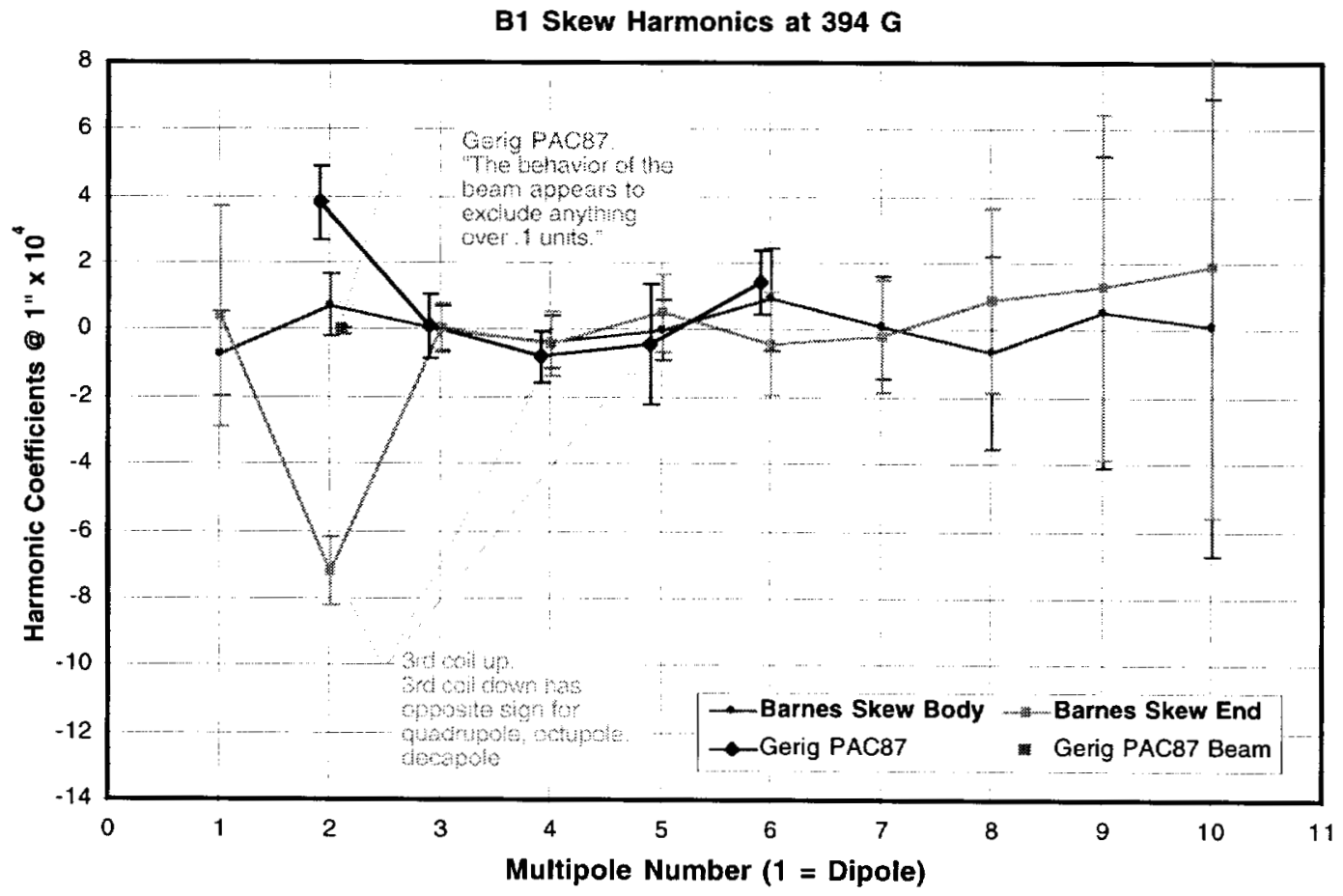

Figure 25. Historical Data for Skew Harmonics.

A few comments are worth making. First, the good agreement (except for the skew quadrupole coefficient) between the Gerig, et al. results and the present analysis is 
reassuring, since the two results are based on the same data. Second, there is a marked discrepancy between the 1970's measurements of the normal sextupole and the current measurements. Third, the spurious skew quadrupole introduced by the probe is apparent. Note that Gerig, et al. developed a simulation of the Main Ring that they compared to its actual performance. This comparison allows a cross check of the chromaticity and the coupling. The chromaticity from the model agreed with the machine, but the coupling did not. As Gerig, et al. put it, "the behavior of the beam appears to exclude anything over 0.1 units."[17]

\section{Conclusion}

To model the effects of the large sagitta in the Scrounge-atron, the harmonic spectra of the $\mathrm{B} 1$ dipoles are required both on the centerline and towards the edge of the aperture, and at the ends separately from the body. I have reported here an analysis of Fermilab measurements taken in the late 1980's that treats each probe position separately. Because of the symmetries in the magnets, only four distinct spectra are required to fully describe the data: normal coefficients on the centerline and at the edge, and skew coefficients in the body and at the end. I have given the spectra in complete form, with the r.m.s. widths of the distributions, as well as in summary form for the significant systematic harmonics. I have also plotted the spectra $v s$. multipole number or reference field (current). Finally, I compared this analysis to historical measurements.

The spectra derived here represent the systematic and random effects that will be encountered in the physical Scrounge-atron. These are the necessary input for detailed dynamic aperture and tracking studies of the accelerator. 


\section{Appendix A: Workbook Sheet Summary}

Table 7. Summary of Calculations Performed by Each Workbook Sheet.

\begin{tabular}{|c|c|c|}
\hline $\begin{array}{l}\text { Analysis } \\
\text { Phase }\end{array}$ & Sheet Name & Calculations Performed \\
\hline \multirow{2}{*}{ 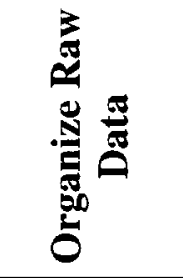 } & Raw & Raw DATATRIEVE output. \\
\hline & Grouped & $\begin{array}{l}\text { Data for each probe position grouped into an outline. } \\
\text { Mean }\left\langle a_{i, j}\right\rangle_{j} \text { and r.m.s. deviation } \sigma_{a_{i, j} l j} \text { for each harmonic } \\
\text { (averaging over magnets). }\end{array}$ \\
\hline \multirow{3}{*}{ 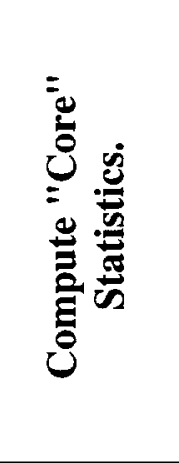 } & Raw $t$ & $\begin{array}{l}t \text {-scores: } t_{i, j}=\left(a_{i, j}-\left\langle a_{i, j}\right\rangle_{j}\right) / \sigma_{a_{i, j} l j} \\
\text { Mean }\left\langle t_{i, j}\right\rangle_{i} \text { for each magnet (averaging over } \\
\text { multipoles). }\end{array}$ \\
\hline & Cut $t$ & Magnets with $\left\langle t_{i, j}\right\rangle_{i}>1.0$ masked out \\
\hline & Cut Raw & $\begin{array}{l}\text { Mean, }\left\langle a_{i, j}^{\prime}\right\rangle_{j} \text {, and r.m.s. deviation, } \sigma_{a_{i, j}^{\prime} l j} \text {, for } \\
\text { each multipole for the magnets that pass the cut } t \text { mask. }\end{array}$ \\
\hline \multirow{3}{*}{ 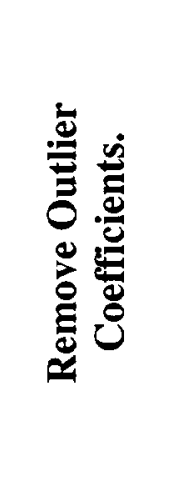 } & T'Scores & $t^{\prime}$-scores: $t_{i, j}^{\prime}=\left(a_{i, j}-\left\langle a_{i, j}^{\prime}\right\rangle_{j}\right) / \sigma_{a_{i, j}^{\prime} j}$ \\
\hline & $t^{\prime}$ Distr & $\begin{array}{l}\text { Plot of distribution and integral of } t_{i, j}^{\prime} \text {, and an } \\
\text { approximate Gaussian fit, used to set the } t_{i, j}^{\prime} \\
\text { cut. }\end{array}$ \\
\hline & $T^{\prime}$ Cut & $\begin{array}{l}t_{i, j}^{\prime} \text { passing the cut determined in } t^{\prime} \text { Distr } \\
\text { Count of the number of coefficients for each magnet } \\
\text { surviving the cut, } N_{t_{i, j}^{\prime} j} .\end{array}$ \\
\hline \multirow{3}{*}{ 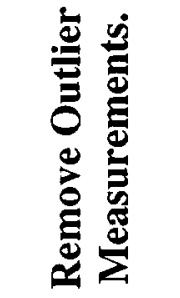 } & \# Distr & $\begin{array}{l}\text { Plot of distribution and integral of } N_{t_{i, j}^{\prime} j} \text {, and an } \\
\text { approximate Gaussian fit, used to set the } N_{t_{i, j}^{\prime} j} \text { cut. }\end{array}$ \\
\hline & \# Cut & $t$-scores for magnets surviving the $N_{t^{\prime}, j j}$ cut. \\
\hline & Filtered & Coefficients corresponding to \# Cut. \\
\hline
\end{tabular}


Table 7, cont.

\begin{tabular}{|c|c|c|}
\hline \multirow{3}{*}{ 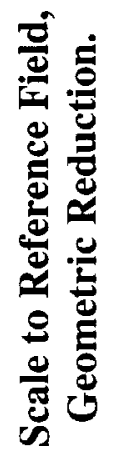 } & scaled & $\begin{array}{l}\text { All coefficients scaled to a common reference field: } \\
\tilde{a}_{i, j}=a_{i, j} \frac{\left(B_{0} \ell\right)_{j}}{B_{0} \ell^{*}}\end{array}$ \\
\hline & Excitation & $\begin{array}{l}\text { Plot of dipole field } v s \text {. current for all measurements at } \\
\text { this current, including least squares linear fit. }\end{array}$ \\
\hline & Rollup & Geometric reduction \\
\hline \multirow{3}{*}{ 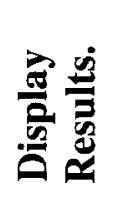 } & Plot Values & Final coefficients and errors collected for plotting. \\
\hline & skew & Plot of skew multipole coefficients. \\
\hline & Normal & Plot of normal multipole coefficients. \\
\hline
\end{tabular}




\section{References}

1. H. D. Glass, Measurement of Harmonic Amplitudes and Phases Using Rotating Coils, 3/9/94, revised 1/19/98, FNAL-MTF-94-004 (Fermi National Accelerator Laboratory, 1998).

2. R. Raja, An Introduction to Harmonic Analysis of Magnets, December 1981, FNALTM-1083 (National Accelerator Laboratory (Fermilab), 1981).

3. L. Michelotti, E. R. Lindstrom, and L. S. Taylor, Combining Multipole Data, in proceedings of the 1987 IEEE Particle Accelerator Conference: Accelerator Engineering and Technology, Washington, DC, 16-19 March 1987, (IEEE), 1645.

4. B. Brown, An Approach to Magnets and Measurements, September 23, 1996, unpublished (Fermi National Accelerator Laboratory, 1996).

5. J. D. Jackson, Classical Electrodynamics, (Wiley, New York, 1975).

6. Other choices are possible, see [4].

7. P. D. Barnes, Jr., FNAL B1 Probe, July 29, 1999, STRON-1999-017 (Lawrence Livermore National Laboratory, 1999).

8. P. D. Barnes, Jr., FNAL Main Ring B1 Dipole Measurement Procedure, July 12, 1999, STRON-1999-018 (Lawrence Livermore National Laboratory, 1999).

9. P. D. Barnes, Jr., DATATRIEVE Procedure to Extract Fermilab Main Ring B1 Measurements, July 12, 1999, STRON-1999-020 (Lawrence Livermore National Laboratory, 1999).

10. B. Brown and D. Harding, personal communication, 1998.

11. B. Brown and D. Harding, personal communication, 1998.

12. A. G. Ruggiero, Dipole Measurement Data Analysis, February 20, 1974, TM-474 (National Accelerator Laboratory, 1974).

13. D. Harding, personal communication, 1998.

14. A. G. Ruggiero, personal communication, 1998.

15. C. Schmidt, personal communication, 1998.

16. J. Prichard, B. A., Remnant Fields in the Main Ring Bending Magnets, January 31, 1975, FNAL-TM-543 (National Accelerator Laboratory, 1975). 
Fermilab B1 Magnet Harmonics

17. R. Gerig, S. Pruss, and F. Turkot, Simulations of the Fermilab Main Ring, in proceedings of the 1987 Particle Accelerator Conference, Washington, DC, 16-19 March 1987, edited by E. R. Lindstrom and L. S. Taylor, (IEEE, New York, NY, 1987), 1123. 